\title{
Modelos de la imagen. El Mago del tarot Visconti
}

\section{A Model for the Image. The Magician of the Tarot Visconti}

Artículo recibido el 9 de enero de 20I7; devuelto para revisión el 5 de mayo de 20I7; aceptado el II de septiembre de 20I7, http://dx.doi.org/IO.2220I/iie.I8703062e.20I8.II2.2635

\author{
Vanessa Alvarez Portugal vanessalvarez.portugal@gmail.com
}

Líneas de investigación Usos de la imagen en el Renacimiento italiano y en la Nueva Espańa; alquimia y magia en imágenes astrológicas durante la modernidad temprana; arcos triunfales.

Lines of research Uses of the image in the Italian Renaissance and in New Spain; alchemy and magic in astrological images in Early Modern times; triumphal Arches.

Publicaciones más relevantes "Las vestiduras de Apolo en la Nueva España", en Arte y patrimonio en Iberoamérica. Tráficos transoceánicos, eds. María Inmaculada Rodríguez Moya, María de los Ángeles Fernández Valle y Carmen Lopez Calderón (Castelló de la Plana: Universitat Jaume I, 2016), 173-I85; "Astros festivos. Imágenes celestes en los arcos triunfales de la Nueva Espańa”, Concinnitas, Revista do Instituto da Artes da UERJ I, núm. 22 (2013), 6-22; "Bildwissenschaft. Una ciencia en construcción”, Anales del Instituto de Investigaciones Estéticas XXXVI, núm. IO5 (2014): 215-254.

Resumen El siguiente artículo presenta un análisis iconológico de una carta del mazo del siglo xv actualmente conocido como el tarot Visconti. La carta adquirió el nombre El Mago, debido al reiterativo uso del motivo iconográfico en mazos de tarot posteriores. Modelos iconográficos anteriores y contemporáneos a esta carta se han encontrado en imágenes provenientes de manuscritos y grabados con contenido astrológico, alquímico y simbólico que datan de los siglos xiv y xv. El presente estudio considera la importancia que estas tradiciones tuvieron en el desarrollo cultural del Renacimiento italiano temprano.

Palabras clave Tarot; imágenes astrológicas; alquimia; arte lombardo; Renacimiento temprano.

Abstract This article presents an iconological analysis of a playing card from the isth century deck now known as the Visconti Tarot. This card 
became named The Magician following the reiterated use of the iconographic motive in later tarot decks. Earlier and contemporary iconographic models of this card have been found in images from manuscripts and prints with astrological, alchemical and symbolic contents dating from the itth and the I5th centuries. The present study considers the importance these traditions had in the cultural development of the early Italian Renaissance.

Keywords Tarot; astrological images; alchemy; Lombard art; early Renaissance. 
DOI: http://dx.doi.org/10.22201/iie.18703062e.2018.112.2635

VANESSA ALVAREZ PORTUGAL

\section{Modelos de la imagen El Mago del tarot Visconti}

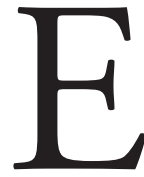

ste trabajo se centra en un análisis de la imagen, desde el punto de vista de la historia de su iconografía, del triunfo El Mago del mazo del tarot Visconti-Sforza, proveniente del Milán del siglo xv. ${ }^{\mathrm{I}}$ Dada la materialidad y la calidad estilística de sus triunfos, así como de la heráldica que muestran, es posible decir que estos mazos tuvieron su origen en la corte milanesa viscontea durante la segunda mitad del quattrocento. Los mazos de cartas para juegos de diversos tipos así como sus diferentes reglas se volvieron populares en Europa a partir del siglo $\mathrm{Xv},{ }^{2}$ sin embargo, hasta la fecha

I. La carta de "El Mago" sólo sobrevive en el mazo del tarot llamado Visconti-Sforza, aunque es muy probable que fuera similar a las cartas del Mago, ahora perdidas, de los otros dos mazos visconteos también del siglo xv: el tarot Brambilla y el tarot Visconti di Modrone. Cabe destacar que esta investigación es un estudio desde la historia del arte, de ninguna manera se intenta hacer una interpretación simbólica del desarrollo del tarot a partir del siglo XIX. A este respecto véase Samuel Liddell MacGregor, The Tarot: its Occult Signification, Use in Fortune-telling, and Method of Play (Nueva York: Occult Research Press, 1988); Gérard Encausse, Papus, Absolute Key to Occult Science: the Tarot of the Bohemians. The Most Ancient Book in the World. For the Exclusive Use of Initiates, trad. A. P. Morton (Londres: Chapman and Hall, I892); Piotr Demiánovich Ouspenski, The Symbolism of the Tarot, trad. Pogossky (Nueva York: Dover Publicactions, 1976); para estudios sobre la relación entre el tarot y la egiptomanía, el hermetismo, la cábala y la Golden Dawn, entre otros, véase Tarot in Culture, ed. Emily E. Auger (Clifford: Valleyhome Books, 20I4); Helen Farley, A Cultural History of Tarot. From Entertainment to Esotericism (Londres-Nueva York: I.B. Tauris \& Co., 2009). Todas las traducciones aquí citadas son mías, salvo que se especifique lo contrario. 2. Al respecto véase Andrea Vitali, "Ludus triomphorum e tarocchi", en Il tarocchino di Bologna, Storia, iconografía, Divinazione dal XV al XX secolo, eds. Andrea Vitali y Terry Zanetti (Bolonia: Edizioni Martina Bologna, 2005), 9-I4; y Andrea Vitali, "Trionfi, trionfini e trionfetti, fra gioco e letteratura", consultado el 2 de julio de 20I5, en http://www.letarot.it/page.aspx?id=238. Así como 
no se han encontrado descripciones o reglamentaciones de los mazos de los tarots visconteos; es precisamente la falta de fuentes primarias respecto al uso de estos tarots lo que da pie a investigaciones, tanto sobre el origen como sobre el desarrollo iconográfico que presentan, y la relación de éste con el uso del mazo.

Varios han sido los estudiosos de los diversos mazos de cartas que han aparecido desde el siglo $\mathrm{XV}$ y que han sido denominados tarot, desde los interesados por el enfoque esotérico ${ }^{3}$ hasta los que incluyen un análisis histórico, como Michell Dummett ${ }^{4}$ o Stuart R. Kaplan, ${ }^{5}$ quien realizó una Enciclopedia del tarot en la que aborda mazos que datan desde el siglo xv hasta el actual. Las investigaciones de Giordano Berti sobre el tarot destacan en particular debido a la incorporación de análisis históricos e iconográficos. ${ }^{6}$ Múltiples mazos de tarots han sido notablemente estudiados desde la historia del arte por Germano Mulazzani y Sandrina Bandera, quienes mediante un minucioso análisis estilístico y de contexto histórico han logrado proponerles autorías y fechas de datación. ${ }^{7}$ Por otra parte, desde una perspectiva filosófica se encuentran los trabajos de Ronald Decker ${ }^{8}$ y de Christophe Poncet, ${ }^{9}$ así como los de Andrea Vitali, ${ }^{\text {IO }}$ los

Robert Steele, A Notice of the Ludus Triumphorum and Some Early Italian Card Games, with Some Remarks on the Origin of the Game of Cards (Londres: Nichols and Sons, Parliament Mansions, I900); y Pietro Sella, "Nomi latini di giuochi negli statuti italiani (sec. XIII-XVIV)", consultado el 2 de julio de 20I5, en http://documents.irevues.inist.fr/bitstream/handle/2042/2547/II\%20TEXTE.pdf.

3. Gertrude Moakley, The Tarot Cards Painted by Bonifacio Bembo for the Visconti-Sforza Family: An Iconographic and Historical Study (Nueva York: The New York Library, 1966); y Heather Mendel, The Syzygy Oracle-Transformational Tarot and The Tree of Life: Ego, Essence and the Evolution of Consciousness (Winchester y Washington: Dodona Books, 2013), entre otros.

4. Michael Dummett, Il mondo e l'angelo i tarocchi e la loro storia (Nápoles: Bibliopolis, 1993).

5. Jean Huets y Stuart R. Kaplan, The Encyclopedia of Tarot, 4 vols. (Connecticut: Game Systems, 1978).

6. Giordano Berti, "I tarocchi in Piemonte", en Tarocchi le carte del regno, la storia, i simboli, il mito, eds. Andrea Ascari, Andrea Vitali y Giordano Berti (Bolonia: Edizioni le Tarot, 1997), I-8; y Giordano Berti y Pietro Marsili, "La diffusione dei tarocchi tra i sec. XV-XIX", en Tarocchi le carte del regno, 9-48.

7. Germano Mulazzani, I tarocchi viscontei e Bonifacio Bembo (Milán: Amilcare Pizzi/Cinisello B., I98I); Sandrina Bandera, Brera, I tarocchi: il caso e la fortuna Bonifacio Bembo e la cultura cortese tardogotica (Milán: Electa, 1999).

8. Ronald Decker, The Esoteric Tarot: Ancient Sources Rediscovered in Hermeticism and Cabalah (Wheaton: Quest Books, 2013).

9. Christoph Poncet, "Un gioco tra profezia e filosofia: i tarocchi di Marsilio", en Il linguaggio dei cieli. Astri e simboli nel Rinascimento, eds. Germana Ernst y Guido Giglioni (Roma: Carocci Editore/Frecce, 20I2), 255-323.

IO. Andrea Vitali et al., Il tarocchino di Bologna, Storia, iconografia, Divinazione dal XV al XX 
cuales destacan por el cuidado que otorga al contexto sociohistórico para tender lazos entre éste y las tradiciones culturales orientales y hebreas. Sin embargo, la relación que existe entre las representaciones de las cartas denominadas triunfos del tarot y las utilizadas en almanaques, manuales o manuscritos de contenido astrológico ha sido abordada escasamente. El principal objetivo de la presente investigación es mostrar el vínculo entre la representación de la carta de triunfo llamada El Mago, de los mazos de tarot Visconti, y las representaciones astrológicas y alquímicas de fuentes anteriores y contemporáneas. Su iconografía será el hilo conductor del texto, de tal forma que resultarán incluidos diversos motivos iconográficos de la cultura occidental provenientes de finales del medioevo, lo cual permitirá lograr una aproximación a la idea y probables usos que se le daba a estos mazos de cartas en el Renacimiento europeo temprano.

Para el presente análisis tomo como referencia las propuestas teórico-iconológicas del historiador del arte y de la cultura Aby Warburg (I866-1929), quien buscó trazar una correspondencia entre la producción de imágenes y la magia astrológica, para así poder explicarlas de acuerdo con las prácticas culturales e intelectuales de la sociedad que las producía. ${ }^{\text {II }}$ De tal modo, se tratará el contexto cultural de la corte de Filippo Maria Visconti (I394-I447) y Francesco Sforza (I4OI-I466), para llevar a cabo un estudio de la imagen dentro de las cartas, así como lo realiza Ewa Sniezynska-Stolot cuando aborda las imágenes astrológicas integradas en diversos salterios; ${ }^{12} \mathrm{y}$, debido a la falta de fuentes escritas, tanto de los mazos visconteos como de ciertos grabados astrológicos y alquímicos, seguiré la propuesta iconográfica de Guy de Tervarent, ${ }^{\mathrm{I3}}$ quien sugiere

secolo (Bolonia: Edizioni Martina Bologna, 2005); y Andrea Vitali, "Trattato del gioco delle Minchiate, un documento sul gioco delle Minchiate del I7I6”, consultado el 2 de julio de 20I5, en http://www.letarot.it/page.aspx?id=257.

II. A este respecto, véase Aby Warburg, "Arte italiano y astrología internacional en el Palazzo Schifanoia de Ferrara (I9I2)”, en Aby Warburg, El renacimiento del paganismo. Aportaciones a la historia cultural del Renacimiento europeo, ed. Felipe Pereda (Madrid: Alianza Editorial, 2005), 4I5-438; y Aby Warburg, "VI Die Einwirkung der Sphaera Barbarica auf die kosmischen Orientierungsversuche des Abendlandes", en Davide Stimilli y Claudia Wedepohl, Per monstra ad sphaeram. Sternglauben und Bilddeutung. Vortrag in Gedenken an Franz Boll und andere Schriften 1923 bis 1925 (Múnich: Dölling und Galitz, 2008), 63-I27. Sobre las investigaciones de Warburg, véase Kurt W. Foster, "Introducción”, en Warburg, El renacimiento del paganismo, II-56.

I2. Ewa Sniezynska-Stolot, "Christian Interpretation of the Zodiac in Medieval Psalters", en Umeni, Casopis, Ustavu Teorie a Dèjin Umeni ceskoslovenské Akademie vèd rocnik XXXVII (Praga: Academia/Nakladatelstvi Ceskoslovenské Akademie ved Praha, 1989), 97-III.

13. Guy de Tervarent, De la Méthode iconologique (Bruselas: Palais des Académis, 196I), 25. 
enfocarse en encontrar la relación entre las representaciones de diversas fuentes, documentos y objetos y, tras ello, dejar abiertas diversas posibilidades de interpretación de acuerdo con el contexto filosófico y cultural.

A continuación, entonces, abordaré inicialmente los problemas de definición de los triunfos y del tarot. Debido a su iconografía y su estilo tardogótico es posible ubicar a los mazos visconteos en el quattrocento italiano e identificarlos en su contexto político con las prácticas culturales correspondientes, propias de la filosofía natural, permeante en la época. ${ }^{14}$ En seguida analizaré la carta de triunfo llamada El Mago, en su relación con otras imágenes semejantes extraídas de diversos manuscritos y grabados, anteriores y contemporáneos, gracias a los que es posible establecer un vínculo con la iconografía astrológi$\mathrm{Ca}^{15} \mathrm{y}$ alquímica, ${ }^{16}$ como se explicará más adelante.

I4. La filosofía natural de la Edad Media y el Renacimiento temprano está influida por el pensamiento aristotélico. Sus propuestas parten de que los seres están compuestos por forma y materia. Para ello véase Cristia Mercer, quien presenta de manera clara algunas premisas base de la filosofía natural escolástica: "Platonism in Early Modern Natural Philosophy. The Case of Leibniz and Conway", en The Perennial Tradition of Neoplatonism, ed. John J. Cleary (Leuven University Press, 1997), II3-II4. Para mayor referencia véase Edward Grant, A History of Natural Philosophy: From the Ancient World to the Nineteenth Century (Cambridge University Press, 2007).

I5. El origen de las imágenes astrológicas se puede encontrar en las denominaciones de las formaciones estelares, por ejemplo, tanto en la determinación de las constelaciones zodiacales como en las personificaciones de los planetas, base del desarrollo de la ciencia astrológica, desde Arato. La iconografía de las fuentes griegas en tratados astrológicos viajó al este, y sirvió para el esparcimiento de conocimiento astrológico con usos adivinatorios y médicos. Dentro de la historia del arte, Warburg fue de los primeros en detectar estas rutas migratorias que incluso fueron expuestas en los proyectos de exposición como la planeada en el Museo Alemán de Múnich en 1927. Véase Aby Warburg, El Atlas de imágenes Mnemosine, vol. II, ed. trad. y notas de Linda Báez Rubí (México: Universidad Nacional Autónoma de México-Instituto de Investigaciones Estéticas, 20I2), 35 .

I6. En la Edad Media, la alquimia era considerada una práctica de transformación de los metales, para lo cual los postulados de Aristóteles sobre la materia resultaban una autoridad. Barbara Obrist, "Die Alchemie in der mittelalterlichen Gesellschaft", en Wolfenbütteler Forschungen, die Alchemie in der europäischen Kultur-und Wissenschaftsgeschichte, ed. Meinel Christoph (Wiesbaden: Herzog August Bibliothek Wolfenbüttel, I986), 40. Para la alquimia en la Edad Media véase Vincent de Beauvais, Speculum naturale (Venecia: Hermannus Liechtenstein, I494). Sin embargo, con el tiempo el proceso de metamorfosis — tanto mediante la destilación como la fermentaciónfue aplicado para ejemplificar la transformación del alma. Véase Titus Burckhardt, Alquimia, significado e imagen del mundo, trad. Ana María de la Fuente (Barcelona: Plaza \& Janés, 1976). Las imágenes del proceso alquímico surgieron, en gran medida, de reintérpretes alquímicos de autores de mitología grecorromana, como Ovidio y Virgilio, entre quienes se encuentran Cornelius 


\section{De triunfos a juegos del tarot}

En Italia, de 1400 a 1600 las palabras tarot y triunfo sirvieron para referirse tanto a las cartas de un mazo, ${ }^{17}$ como a los distintos juegos a los que se podía jugar con ellos. ${ }^{18}$

El término tarot deviene de los triunfos, figuras alegóricas que se añadían a un mazo de generalmente 40 cartas numerales y 16 de personajes de corte. ${ }^{19} \mathrm{El}$ vocablo tarocchi tiene muchas acepciones dependiendo de la época en que se

Agrippa, Michael Maier e incluso Francis Bacon. Véase Thomas Willard, "The Metamorphoses of Metals: Ovid and the Alchemists", en The Metamorphoses of Metals: Ovid and the Alchemists, eds. Alison Keith y Stephen Rupp (Toronto: CrRs Publications, 2007), I56-I58. Algunos ejemplos de imágenes alquímicas se encuentran en los frescos de la capilla Scrovegni de Padua, de principios del siglo XIV, y en famosos manuscritos del siglo XVI como el Splendor Solis. Splendor solis oder Sonnenglanz: Studien zu einer alchemistischen Bilderhandschrift, ed. Jörg Völlnagel (Múnich: Deutscher Kunstverlag, 2004).

17. En el quattrocento italiano se usaba la palabra triumphi para referirse al mazo compuesto por 78 cartas, de las cuales 22 eran alegóricas y 56 representaban a la corte — paje, caballero, reina y rey-y números. De finales del quattrocento al cinquecento, al mazo de los triumphi se le denominó ludus tarochorum o juego de tarot. En el siglo Xvi al mismo mazo se le denominó tarocchi. Literatos, como Giulio Cesare Croce se refirieron a las cartas triunfales como triumphi dé tarrochi, mientras que otros, como Notturno Napolitano, para referirse a las mismas, utilizaron el término trionfi o triumphi. Andrea Vitali sugiere que estas cartas eran llamadas por los jugadores trionfi en tanto que poseían en el juego un valor superior al de las numerales y las de la corte. Véase Vitali, "Trionfi, trionfini e trionfetti".

I8. Contemporáneamente, con el término ludus triumphorum o ludus ad triumphos se nombró al juego en el cual se utilizaban las cartas numerales y las cartas de corte. Este juego incluía unas cartas denominadas trionfi, las cuales constituían la baza — también llamadas brisca-, es decir, la carta que sale del mazo barajeado y guía el resto del juego. Ésta se descubría al inicio de la partida a la voz ludus ad triumphos. Véase el término triumphorum, en Sella, "Nomi latini di giuochi", 213. En sí existieron diversos juegos de azar. En I550 Cardano menciona el triumphi, el triumfeti y el sequentium tarochi (véase Archaeologia, vol. LVII, citado en Steele, A Notice of the Ludus Triumphorum, 10). El ludus ad trapollinus era considerado un juego de trionfi, mencionado por Pietro Sella. Por otra parte, en el volumen VII del Dizionario della Lingua Italiana de I830 se le llama trionfo a la carta nombrada por el jugador, mientras que el segundo volumen del Dizionario Piemontese Italiano Francese dice que el trionfi abarca los juegos de cartas como el trionfetti, trionfini, chartularum lusus, el trionfi y los juego de los triunfos. Vitali, "Trionfi, trionfini e trionfetti".

19. Un ejemplo más sobre la vastedad de uso del término triumphi es que a principios del quattrocento existía un mazo de cartas denominado triumphi, el cual fue ideado por Marziano da Tortona para Filippo Maria Visconti. Éste contenía imágenes de divinidades clásicas, de figuras de aves como águilas, fénix y tortugas. Para profundizar sobre el término tarot y triunfo, como mazos y como juego, véase Tania Vanessa Alvarez Portugal, "El mago, el coche, el ermitaño y el 
DOI: http://dx.doi.org/10.22201/iie.18703062e.2018.112.2635

I40

VANESSA ALVAREZ PORTUGAL

emplee. Para facilitar el uso de términos, aclaro que me referiré con la palabra tarot a las 22 cartas alegóricas de un mazo de 78 , entre las que se encuentran las numerales y las de figuras de la corte.

En 1526 Francesco Berni escribe en Roma las primeras reglas del juego del tarot, Il Capitolo del Gioco di Primera. ${ }^{20}$ En el siglo Xvi se consideraba que los juegos de tarot no eran de azar porque involucraban el uso de la memoria mediante alegorías y personificaciones representadas en los triunfos, razón por la cual no estuvieron proscritos por la Iglesia. ${ }^{2 \mathrm{I}} \mathrm{Sin}$ embargo, en tanto que juegos de cartas, fueron condenados por el vicio que causaban y por los delitos que se perpeturaban en torno a la mesa de juego. ${ }^{22}$

El tarot fue muy popular en la corte milanesa, como lo prueban los testimonios sobre Alfonso de Este (I476-I534), Galeazzo Maria Sforza (I444-I476) y Ludovico Sforza, el Moro (I452-I508), así como la gran cantidad de cartas conservadas en el depósito del castillo sforzesco de Milán. ${ }^{23}$ En el Palacio Borromeo se encuentra un fresco llamado la Stanza dei giochi, en donde se representa a los jugadores del tarot con una actitud seria.

Carlo Pisarri en su Istruzioni necessarie per chi volesse imparare il giuoco dilettevolte delli Tarocchini di Bologna, escrito en 1754, y que dice estar basado en otro manual más antiguo, informa que durante las partidas está prohibido hablar porque el propio juego involucra una gran atención y ejercicio de memoria. ${ }^{24}$

colgado del tarot Visconti-Sforza”, tesis de maestría (México: Universidad Nacional Autónoma de México-Facultad de Filosofía y Letras, 20I2), IO-I5; y Andrea Vitali, "Trionfi, trionfini e trionfetti". 20. Berti y Marsili, "La diffusione”, I4.

2I. Sobre las referencias a prohibiciones de juegos de cartas desde el siglo xiv, véase Steele, $A$ Notice of the Ludus Triumphorum, II. Otro tipo de juego que utilizó las cartas del tarot fue el desarrollado por Troilo Pomeran, quien compuso un poema (poemeto) en el que une las 22 figuras del tarot al nombre de mujeres venecianas solteras, creando así el "juego de las mezclas" (degli abbinamenti), según una costumbre de asociaciones y de motivos verbales que se mantuvieron entre 1600 y 1700 , de particular dificultad para leer en público. Más tarde, esta práctica se utilizó junto con la sátira política de I8oo, cuando a los triunfos se les añadió la personalidad política del momento. Lucia Nadin Bassani, Le carte da Gioco a Venecia. L'arte dei cartoleri (I400-I700) (Venecia: Centro Internazionale della Grafica, 1989), I7.

22. Entre los cuales se encuentran el robo y el uso de la violencia. Véase Giovanni Dolcetti citado en Vitali, “Trionfi, trionfini e trionfetti”. Testimonios al respecto pueden encontrarse en archivos de Venecia, ciudad en la cual desde el cinquecento se hallan numerosos comentarios de la difusión del juego de cartas en todos los estratos sociales. Nadin, Le carte da Gioco a Venecia, i6.

23. Nadin, Le carte da Gioco a Venecia, 17.

24. Este mazo consiste en 64 cartas y es para cuatro personas, en el cual juegan dos contra dos. $\mathrm{Al}$ principio cada uno toma una carta al azar y quien tenga la carta más alta inicia la partida. El 
Puede que el juego del siglo XviII así como el representado en la stanza dei giochi guarde un contenido literario-filosófico, como los Triunfos de Petrarca, o incluso alquímico ${ }^{25} \mathrm{o}$ astrológico, como llegó a ser frecuente en la formación humanista, según se verá a continuación.

Me parece interesante destacar que pese a que las menciones de cartas de juego inician desde 1377 , con el De moribus et disciplina humani conversationis de Johannes Teutonicus, las referencias a los triunfos o al tarot son escasas hasta I484, salvo lo señalado por Decembrio sobre las cartas de dioses y animales de Filippo Maria Visconti hechas por Marziano da Tortona alrededor de I4II; el minchiate de Aurelia Visconti Gonzaga entre I427 y I447; y ya más específicamente en 1484 un mazo de tarocchi hecho para Ascanio Maria Sforza. ${ }^{26}$ Estimo que fue quizás el uso privado de estos mazos la razón por la cual se encuentran tan pocas menciones de los mismos en la literatura popular.

Son pocas las fuentes del siglo Xv que hablan sobre el uso aristocrático filosófico del tarot, como lo describe Vicenzo Imperiali para I550 en la Risposta a la inventiva contro il gioco del Tarocco, escrita en Ferrara por Flavio Alberti Lillio, en donde afirmó que, "El juego del tarot es de señores, príncipes, reyes, barones y caballeros" ${ }^{27}$ Tras un examen detenido es notable que las fuentes tienden a marcar una diferencia entre el uso que cada grupo social le imprimía al

objetivo es hacer tiradas de cartas en serie. Hay cinco series, la de las espadas, los bastos — que siguen el mismo orden-y la de las copas y los oros. Éstas están compuestas por diez cartas, cuyo orden en los bastones y las espadas es de rey, reina, caballo, paje, diez, nueve, ocho, siete y seis (el rey es el más fuerte); mientras que en las copas y en las de oros, el orden es el contrario. La quinta serie la conforman los triunfos, en el juego llamada la serie Granda, ahí el orden es: El Ángel, El Mundo, El Sol, La Luna, La Estrella, La Flecha, El Diablo, La Muerte, El Traidor, El Viejo, La Rueda, La Fuerza, La Justicia, La Templanza, El Carro, El Amor; los cuatro Mori (papesa, papa, emperador y emperatriz) no tienen un orden, sólo "toman" (o vencen) a la carta anteriormente jugada; El Bagatela y El Loco recorren toda la secuencia por lo que se llaman contatore; véase Carlo Pisarri, Istruzioni necessarie per chi volesse imparare il giuoco dilettevolte delli Tarocchini di Bologna (Bolonia: Ferdinando Pisarri, I754), I6-18.

25. Bandera, Brera, I tarocchi, 18.

26. Realizado por el pintor Antonio de Cicognara. Ascanio María Sforza fue nieto de Filipo Maria Visconti. Bordigallo, Chronache di Cremona, citado en Steele, A Notice of the Ludus Triumphorum, $\mathrm{I} 2$.

27. "Il gioco del tarocco è da Signori, Principi, Re, Baroni, et Cavalieri", en Berti y Marsili, "La diffusione", I7. Esta aserción sirve de base para Berti y Marsili quienes consideran que el tarot tuvo un origen aristocrático. Por otra parte, Vitali considera que su origen es popular, y que la causa por la que no sobreviven cartas populares de tarot se debe a la constante manipulación de la que eran objeto. 
juego del tarot. Así, resultaría que el uso popular consideraría juegos azarosos con los triunfos, como la brisca en el ludus triumphorum; ${ }^{28}$ mientras que, para Imperiali, el tarot se define como un juego aristocrático filosófico — como el minchiate. Para el canónico Pierre Grégoire, el tarot poseía elementos de erudición que otros juegos de cartas, como la basseta, no tenían. ${ }^{29}$

\section{Los tarots Visconti}

Existen actualmente tres mazos de tarot determinados visconteos: el tarot Brambilla o tarot Brera-Brambilla, ${ }^{30}$ el tarot Visconti di Modrone o tarot Visconti

28. Véase la nota I8.

29. Véase Vitali, "Ludus triomphorum e tarocchi”, I5. Entre los mazos del tarot del siglo xv que contenían material filosófico podemos encontrar el Tarocchi di Alessandro Sforza (ca. 1450 y I460) de Ferrara y el Tarocco leber de probable origen veneciano, que contiene ocho cartas de triunfos inspiradas en divinidades griegas, las cuales están enumeradas y portan leyendas en latín que brindan su significado, mientras que las cartas de la corte retratan personajes históricos de la antigüedad (Berti y Marsili, "La diffusione", 20 y 44); el tarot de Carlos VI (de entre I470 y I480), que obtiene su nombre de la errónea identificación con las cartas mencionadas en un libro de cuentas de Carlos VI de Valois de I392; así como el tarocchino de Bolonia, el tarot siciliano y el austriaco, cuyas reglas resultan similares (Vitali, "Ludus triomphorum e tarocchi", 23). Asimismo, el minchiate florentino, que contiene cartas de las virtudes teologales, de los elementos y de los signos zodiacales. Del minchiate florentino cuyas reglas son principios moralizantes o filosóficos da noticia la condesa Aurelia Visconti Gonzaga de Milán (de I427 a 1447) (véase Steele, $A$ Notice of the Ludus Triumphorum, 8-9). Sobre la forma de jugar, se encuentra el manuscrito Regole del nobile e dilettevole gioco delle Minchiate, compuesto por el Avv. Niccolò Onesti (Roma, I7i6), ubicado actualmente en la Biblioteca de Castiglion Fiorentino. El tratado proviene de la casa del seńor Giuseppe Cagnoni, sobrino y heredero del histórico Giuseppe Ghizzi; así como las Regole genereli del giuoco delle minchiate, con divere istruzioni brevi, e facili per bene imparare a giuocarlo (Florencia, 178I). Véase también Samuel Weller Singer, Researches into the History of Playing Cards, with Illustrations of the Origin of Printing and Engraving on Wood (Londres: T. Bensley and Son for Robert Triphook, I8I6), 351-352.

30. Hay todavía un debate sobre el origen de los mazos. Concuerdo con Sandrina Bandera en sus conclusiones, quien data el origen de estas cartas entre I442 y I445, las cuales toman el nombre de Giovanni Brambilla, quien las compró en Venecia alrededor de 1900. En 1916 el mazo se le ofreció a John Pierpont Morgan por 20 mil libras esterlinas, mas no aceptó la oferta (Bandera, Brera, I tarocchi, 66). El mazo originalmente tenía 78 cartas, de las cuales, 44 fueron compradas por el gobierno de Milán en I971: dos triunfos, los llamados El Emperador y La Rueda de la Fortuna; siete personajes de la corte y las cartas numerales de las cuatro figuras (espadas, bastos, oros y copas). Estas cartas se encuentran en la Pinacoteca Brera de Milán (Bandera, Brera, I tarocchi, I4). 
Cary-Yale, ${ }^{31}$ y el tarot Visconti-Sforza Colleoni-Baglioni o tarot Visconti-Sforza Pierpont-Morgan-Bergamo. ${ }^{32}$ Cobran el nombre Visconti debido a la presencia, en algunas de sus cartas, de la heráldica de esta casa milanesa — así como el último mazo la contiene de la familia Sforza-, aunado al del coleccionis-

3I. Para Sandrina Bandera estas cartas se hicieron antes de 4447 (Bandera, Brera, Itarocchi, 2I). En 1947 las cartas las compró Melbert B. Cary Jr. diseñador gráfico e importador interesado en la imprenta y, junto con su esposa Mary Flager Cary, en las cartas de juego. Tras la muerte de la señora Cary en 1967, su colección de cartas, incluidas las del mazo Visconti di Modrone, fueron donadas a la Biblioteca Beinecke de la Universidad de Yale donde se encuentran disponibles en "Visconti Tarot Cary Collection of Playing Cards", consultado el 8 de septiembre de 20I6, en http://brbl-dl.library.yale.edu/vufind/Search/Results?lookfor=Visconti+Tarot\&type=tag. Este mazo, actualmente incompleto, está compuesto por 60 cartas, entre las cuales 39 son numerales, I7 son de figuras de la corte, y in son triunfos: las tres iconográficamente identificadas por Bandera como La Caridad, La Fe y La Esperanza (que Kaplan identifica con El Papa, La Papesa y La Estrella), la Emperatriz, El Emperador, Los Enamorados, El Carro, La Fuerza, La Muerte, El Juicio y El Mundo (Bandera, Brera, I tarocchi, 52). Este mazo presenta ciertas peculiaridades iconográficas que lo diferencian de los otros dos: la tipología del hombre anciano con la barba que representa al rey de espadas de este mazo contrasta con la tipología juvenil del rey de espadas y del rey de oros del mazo Brambilla y con los cuatro reyes jóvenes del mazo de la colección Baglioni; también es importante destacar que en los triunfos y en las cartas de personajes se refleja el clima de la corte, pues se representa a los personajes acompañados por su valet.

32. Tras un análisis iconográfico, Bandera considera que este mazo se realizó entre 1450 —año en que Sforza tomó el poder-y I455 (Bandera, Brera, I tarocchi, 2I). Este mazo tomó el nombre de los últimos propietarios, los condes Alessando Colleoni y Francesco Baglioni. Cuando pertenecía a Alessando Colleoni, a finales del siglo XIX, el tarot tenía 75 cartas (sólo faltaban El Rey de Oros, El Diablo y El Mundo). Según William M. Voelkle, el conde Emiliano di Parravicino cuenta que un día Francesco Baglioni persuadió a Alessandro Colleoni para intercambiar 26 cartas por un retrato de una condesa Colleoni hecho por Galgario. Baglioni heredó luego sus cartas a la Academia Carrara de Bérgamo (William M. Voelkle, The Visconti Sforza Tarots). En I9ı Colleoni vendió a John Pierpont Morgan 35 cartas por una suma de alrededor de 200 mil francos (Pierpont Morgan Library and Museum, Additional Unpublished Information from the Internal Files: Black Binders, M.630). Aún quedan 13 cartas numerales en la colección de la familia Colleoni en Bérgamo. Actualmente el mazo ha perdido además la carta del Caballero de Oros. Las cartas de la Academia Carrara son La Luna, La Estrella, La Torre, El Emperador, y siete cartas numerales. De este mazo, seis triunfos: La Luna, La Estrella, El Mundo (actualmente en la Accademia de Carrara), La Fuerza, La Temperanza y El Sol (ahora en la Pierpont Morgan Library) se realizaron a finales del quattrocento, por Antonio Cicognara como sustitutos de cartas que se habían perdido. El mismo artista procedió a extender su restauración, usando colores más fuertes, sobre todo el mazo (Bandera, Brera, I tarocchi, 64). En el mazo Visconti-Sforza se da una individualización de los personajes y una mayor monumentalidad por los gestos imperiosos de las figuras. Para una descripción pormenorizada de cada uno de los mazos, sus similitudes, diferencias y las cartas que actualmente conforman cada mazo, véase Alvarez "El Mago, El Coche", 29-34. 
ta que los dio a conocer, y al del actual repositorio donde se encuentran. Son muy escasos los datos que se tienen respecto a los tarots Visconti. Gracias a los análisis iconográficos y estilísticos que han llevado a cabo algunos autores como Sandrina Bandera y Algeri, entre otros, es posible ubicar su origen en el norte de Italia en el siglo XV.

Los mazos de tarot de la corte Visconti están hechos de cartón. Las cartas están pintadas al estilo de las miniaturas tardogóticas lombardas de finales del trecento, ${ }^{33}$ las cuales se caracterizan por la representación de escenas cotidianas y la inclusión de naturaleza. ${ }^{34}$ Cada carta se planeó, dibujó y pintó al temple. Algunas se recubrieron con lámina de oro o plata ${ }^{35}$ y tienen decoración de taroccato. ${ }^{36}$ Los tres mazos contienen representaciones temáticas similares y escudos heráldicos. Es por todas estas razones por las que se considera que se hicieron en un entorno cortesano. En ninguno de los tres mazos aparecen los nombres de las cartas posteriormente identificadas como triunfos, como se explicará más adelante, ni un número con el cual conocer el orden que debieron guardar. ${ }^{37}$ Algunas cartas tienen un pequeńo agujero en el marco superior central, lo que

33. El mecenazgo visconteo desde finales del trecento favoreció los códices iluminados, la orfebrería y los pequeños objetos de colección, de entre los cuales se encuentra un gran número de manuscritos iluminados franceses. Sandrina Bandera, "Il tardogotico a Milano: la corte, le famiglie nobili e il Duomo", en Pittura a Milano dall'Alto Medioevo al Tardogotico, ed. Mina Gregori (Milán: Cariplo, Cassa di Risparmo delle Provincie Lombarde, 1997), 6I-62.

34. El estilo pictórico lombardo de la segunda mitad del trecento se basó en el estudio de la naturaleza — sobre todo en la representación de los animales — que era luego plasmado en la escala del arte deseado (orfebrería, miniatura). A decir de Bandera, es Giovannino de'Grassi quien con su tendencia geometrizante e influencia de la miniatura figurativa bolońesa y veneciana estructura la línea general de la pintura tardogótica lombarda desde finales del trecento. De acuerdo con la autora, el estilo tardogótico es identificable en las cartas por medio de los trazos sinuosos de los vestidos y del uso del simbolismo en escenas de la vida privada. De igual forma, la autora identifica la representación de caballos y tabernáculos en común con otros documentos artísticos del fondo visconteo-sforzesco del quattrocento. Bandera, "Il tardogotico a Milano", i8.

35. Bandera, "Il tardogotico a Milano", I3.

36. Técnica decorativa de la lámina a base de un punzón, la cual brinda volumen e imprime un efecto tridimensional a la carta cuando la lámina se encuentra en el fondo.

37. Ésta es la razón por la cual los términos con los que me referiré a ellas son los convencionales en la época actual, es decir: El Loco, El Mago, La Sacerdotisa, El Papa, La Emperatriz, El Emperador, Los Enamorados, El Colgado, El Ermitaño, La Torre, El Diablo, La Muerte, La Estrella, La Luna, El Sol, La Fuerza, La Templanza, La Justicia, El Carro, El Juicio Final, La Rueda de la Fortuna, El Mundo. Para un comentario más amplio sobre las diversas nomenclaturas aplicadas a los triunfos con base en referencias iconográficas, véase Berti y Marsili, "La diffusione", II; Pisarri, Istruzioni necessarie, I6-I8; Steele, A Notice of the Ludus Triumphorum, 8-9. 
da pie a pensar que incluso podrían haber sido colgadas en un orden variable. Por otra parte, indistintamente, los triunfos de estos mazos presentan alteraciones de color en algunos sitios, probablemente como signos de uso o residuos de otras sustancias con las que pudieron haber estado en contacto..$^{38}$

Ha habido un serio debate sobre la autoría de los mazos visconteos basado en estilos artísticos y probable datación de las cartas, ${ }^{39}$ sin embargo, la opinión más aceptada hasta el momento es que surgieron por obra de Bonifacio Bembo. ${ }^{40}$ Bandera indica que Bonifacio Bembo (I447-I477) fue el autor de los mazos de tarot visconteos, en los que reconoce la influencia veneciana — de Pisanello (I395-I455), de Franceschino Zavattari y de Gentile da Fabriano (I370I427) - manifiesta en el refinamiento de las figuras, en la formación de los esquemas y en el empleo del cartón. Bandera ve en la elegancia de Bonifacio Bembo la asimilación de la obra de Gentile da Fabriano y de Pisanello; también encuentra una influencia de este último en la riqueza narrativa y la refinada ejecución de la obra de Bembo, notable en los frescos de la capilla Berzoni en San Fermo de Verona ( $c a$. I426), que lentamente fue absorbida en la producción de los otros dos mazos, claramente ajustados a la órbita cultural milanesa, y sobre todo a Zavattari. ${ }^{4}$

Los mazos visconteos actualmente son considerados como los primeros mazos de tarot en tanto que sus triunfos presentan figuras alegóricas que son

38. Además de las diferencias iconográficas y que usan diversos materiales, también tienen una pequeña variación en el tamaño. Por ejemplo las cartas del tarot Visconti-Sforza Colleoni-Baglioni o el tarot Visconti-Sforza Pierpont-Morgan-Bergamo miden $8.7 \times 17.6 \mathrm{~cm}$, las del tarot Visconti di Modrone o el del Visconti Cary-Yale miden $9 \times 18.9 \mathrm{~cm}$, mientras que las del tarot Brambilla o tarot Brera-Brambilla miden $8.9 \times 17.8 \mathrm{~cm}$. Véase Alvarez, "El Mago, El Coche", 29-34.

39. Desde la consideración de Francesco Zavatarri, activo en Milán en la primera mitad del siglo Xv, o algún miembro de esta familia de pintores lombardos; de Michelino da Besozzo (ca.1370-I455), pintor de estilo gótico muy activo en Siena, Milán, Vicenza, Verona y Venecia, heredero estilístico de Pisanello y de Gentile da Fabriano; a la consideración de Bonifacio Bembo, miembro de una familia de pintores cremoneses de mediados del siglo xv. Para aproximarse a los análisis y estudios comparativos al respecto que retoman las opiniones de los investigadores del tarot como Adolfo Venturi, Pietro Toesca, Roberto Longhi, Carlo Ludovico Ragghianti, Ludwig Wittgens, N. Rasmo, Samek Ludovici y Gertrude Moakley, entre otros, véase Mulazzani, I tarocchi viscontei, 36; Bandera, Brera, I tarocchi, I5; Bandera, "Il tardogotico a Milano", 64-65; Berti y Marsili, "La diffusione," 2o. Véase también Alvarez, "El Mago, El Coche”, 39-47.

40. Sandrina Bandera tras análisis estilísticos, iconográficos e investigación de archivo, concluye que los tres mazos de tarot pudieron haberse producido en el taller de los Bembo. Véase Bandera, Brera, I tarocchi, 53.

4I. Bandera, Brera, I tarocchi, 53. 
retomadas en mayor o menor medida por otros mazos de tarot a lo largo del tiempo.

Hay que notar, sin embargo, que los triunfos de los diferentes mazos visconteos, aunque similares, presentan diferencias iconográficas particulares, como es el caso del triunfo El Juicio del mazo Visconti di Modrone y del ViscontiSforza (figs. I y 2). Esto hace posible pensar que pudo haber existido una cierta secrecía y reglamentación en cuanto a la producción de tarots y cartas de juego en general en el siglo xv a decir de Emilio Orioli, en 1908. Este autor presenta el resumen del contrato notariado por Alberto Argellata (en Bolonia, I477) en donde Roberto Blanchelli pide a Pietro Bonozzi realizar una cierta cantidad de cartas y triunfos a la vez que se le sugiere guardar en secreto las imágenes de las dichas cartas. ${ }^{42}$

\section{El tarot en la corte de Milán}

Los mazos visconteos hacen referencia a personajes de la corte milanesa del siglo XIV: en el tarot Brambilla algunas cartas sin figuras tienen características de la heráldica viscontea, como por ejemplo, el as de espadas que incluye la leyenda "a bon droite phote mante [nir]" (un buen derecho [iporta?]); el as de bastos y el cuatro de copas tienen escrito "a bon droiyt" (un buen derecho), lema de los duques milaneses; a su lado se representa la moneda de Filippo Maria Visconti, ${ }^{43}$

42. En el contrato se establece que Bonozzi debía hacer las cartas basándose en un modelo, pero de tal forma que no resultaran iguales, o Bonozzi estaría obligado a rehacerlas. Debía ocupar en esta labor 18 meses. Además se incluían cláusulas de exclusividad, pues Bonozzi no debía dejar que nadie de su taller hiciera, vendiera o mostrara las cartas para nadie más. Blanchelli le dispensaría el cartón necesario para hacer dicte carte o vero triumphi. Véase Emilio Orioli, "Sulle carte da giuoco a Bologna nel secolo Xv", en Il Libro e la Stampa, ańo II (I908): II2; Vitali, "Ludus triomphorum e tarocchi”, I6.

43. Puesto que su hermano mayor Giovanni Maria Visconti era el heredero del ducado de Milán, Filippo fue enviado a Pavia, entonces importante centro humanístico. Una vez que su hermano fue asesinado en I4I2, Filippo Maria tomó el poder y se volvió el tercer duque de Milán. Su biografía corrió a cargo del humanista Pier Candido Decembrio (Pavia, I392-Milán, I477), quien había recibido su educación en Pavia y se encontró activo en la corte de Milán, "fue uno de los más importantes humanistas; miembro de la secretaría viscontea de I4I9 a I447, y de aquella de la República Ambrosiana del 49 al 50, fue a Roma de I450 a I456, a Nápoles a finales de 1459 y finalmente fue huésped de Borso d'Este en Ferrara de I466 a I474. Traduce del griego y del latín, y dejó además de numerosos Opuscula historica (de la cual forma parte la vida de Filippo Maria Visconti), un epistolario que es una fuente preciosa de información sobre la vida de su 
cuyas dos caras se reproducen en todas las cartas de la figura de los oros. Algunas cartas con figuras a caballo presentan motivos e impresiones pertenecientes a Filippo Maria Visconti, así es la moneda sobre la vestimenta del caballero de copas, la corona ducal con laurel y palma sobre el caballero de oros y el pañuelo en el caballero de bastos.

El tarot Visconti di Modrone presenta en los oros la moneda acuñada por Filippo Maria Visconti. En la carta El Amor aparece el escudo de armas de Visconti y el de Saboya. La inclusión de los escudos de ambas familias en la representación del rito matrimonial denominado Dextrarum junctio, ${ }^{44}$ sugiere la representación de un matrimonio. La carta podría referirse a la unión de Filippo Maria Visconti con Maria Saboya (I4II-I469) de I428. Por su parte, en el mazo del tarot Visconti-Sforza aparecen motivos de la heráldica Visconti y de la Sforza, como la figura de tres anillos unidos, de Francesco Sforza, lo que permite sugerir la datación del mazo luego de I447, año de la muerte de Filippo Maria, o al menos después de I450, cuando tras el periodo de la República Ambrosiana, inició el ducado de Francesco Sforza, quien había contraído matrimonio con la hija de Filippo Maria Visconti, Bianca Maria (I472-I5IO) en $\mathrm{I} 44 \mathrm{I} .{ }^{45}$

tiempo" (fu uno dei più importanti umanisti; membro della segretaria viscontea dal I4I9 al I447, e di quella della Repubblica Ambrosiana dal 49 al 50, fu a Roma dal I450 al I456, a Napoli fino al I459 e infine ospite di Borso d'Este a Ferrara dal I466 al I474. Tradusse dal greco e dal latino e lasciò, oltre a numerosi Opuscula historica [di cui fa parte la vita di Filippo Maria Visconti], un epistolario che è una fonte preziosa d'informazioni sulla vita del suo tempo), en Pier Candido Decembrio, Vita di Filippo Maria Visconti, ed. Elio Bartolini (Milán: Adelphi Edizioni S.P.A., 1983), 52. Decembrio tuvo como modelo para la Vida de Filippo Maria Sforza, la Vida de Augusto, escrita por Suetonio, véase Ernst Ditt, Pier Candido Decembrio, contributo alla storia dell'umanesimo italiano (Milán: Ulrico Hoepli Libraio del R. Istituto Lombardo di Scienze e Lettere, I93I), 65. Para mayores referencias sobre el humanismo, véase Jill Kraye, The Cambridge Companion to Renaissance Humanism (Londres: The Warburg Institute/Cambridge University Press, 200I).

44. Nombre que recibe la práctica de estrechar la mano derecha en el ceremonial del matrimonio. Christophe Poncet, "The Judgement of Lorenzo", Bruniana \& Campanelliana, Richerche Filosofiche e Materiali Storico-testuali, año XIV, núm. MMVIII (2008): 543. La Dextrarum junctio está presente en las dos cartas sobrevivientes de El Amor, una del mazo Pierpont-Morgan y la otra perteneciente al Brera-Brambilla, aunque contienen diferente heráldica.

45. Puesto que el matrimonio de su hija podía servir a Filippo Maria Viconti para hacer relaciones políticas, Filippo había considerado primero casarla con Carlos Gonzaga de Mantua, y luego con Leonello de Este. Stuart R. Kaplan, "The Visconti and Sforza Families and Heraldics Devices", en Visconti Sforza Tarot Deck Fifteenth Century (Bérgamo: Grafica Gutenberg, 1975), 6-8. 
Para Mary Hollingsworth, desde el ducado de Filippo Maria Visconti, existió una necesidad política que fomentó la presencia de humanistas al servicio del ducado, y ésta era la de hacer propaganda a un régimen monárquico muy impopular, al exponer sus beneficios a diferencia de los "inestables" Estados electivos, por ejemplo, mediante el patrocinio a las artes, como una forma de mostrar la estabilidad, el poder y el prestigio del ducado. ${ }^{46}$ Entre los humanistas al servicio de Filippo Maria Visconti se encontraron el embajador de la corte Tommaso Moroni, quien, de acuerdo con Decembrio, era un maestro de la mnemotecnia, ${ }^{47}$ y Ferdinando Betico, de quien dice "parecía haber asumido la capacidad divinatoria con la vida misma”. ${ }^{8}$

El biógrafo de Filippo Maria Visconti, Decembrio, escribe que el duque desde joven gustaba mucho de los juegos, de los dados, de las cartas, del ajedrez y de los astrágalos —un tipo de juego que por su evocación homérica fue muy practicado_-;49 menciona además que en I4I5 Visconti pidió a Marziano da Tortona un juego de cartas de divinidades clásicas y de animales — como

46. Mary Hollingsworth, El patronato artístico en la Italia del Renacimiento de I400 a principios del siglo XVI (Madrid: Akal, 2002), I78.

47. Tommaso Moroni (I408-I476), “originario de Rieti, en algún momento de su vida se hizo evidentemente, también maestro de arte mnemónica: [...] soldado, profesor, secretario de la curia romana, hombre de Estado, diplomático, embajador de Filippo Maria Visconti, de Francesco Sforza y, en su vejez, de Galeazzo Maria, o en la más escuálida miseria o en medio de las comodidades y los honores, fue uno de los más bizarros aventureros del siglo xv (reatino [...] a un certo punto della sua vita si fece, evidentemente, anche maestro d'arte mnemonica: [...] soldato, professore, segretario della curia romana, uomo di stato, diplomatico, ambasciatore di Filippo Maria Visconti, di Francesco Sforza e, nella sua vecchiaia, di Galeazzo Maria, or nella più squallida miseria, or in mezzo agli agi e agli onori, fu uno dei più bizzarri avventurieri del secolo xv"), en Mario Borsa, "Pier Candido Decembrio e l'Umanesimo in Lombardia", Archivio Storico Lombardo Giornale della Società Storica Lombarda X, año XX (1893): 53.

48. "sembrava aver assunto la capacità divinatoria con la vita stessa", en Decembrio, Vita di Filipo Maria Visconti, in6. "Dovrebbe trattarsi del famigerato Fernando da Cordoba, dalla memoria rapaci, voraci, tenaci come gliela definì il Valla. Il 6 Giugno 1446 stupì i Genovesi disputando, in gara con i più dotti della città, ventotto questioni: dalla teologia alla poesia: 'Ut Tagis in morem e sulco erutus' dice di lui il Decembrio. E in una civiltà dove ogni principotto era subito un divinus Augustus e un Marte il più scalcinato dei capitani di ventura, a dire di uno fornito di capacità divinatore non ci si poteva non richiamare a Tages, nipote di Giove, uscito all'improvviso da un solco tracciato dal bifolco Tarconte per insegnare agli Etruschi l'aruspicina, poi codificata appunto nei libri Tagetici", en Decembrio, Vita di Filipo Maria Visconti, 205.

49. Decembrio, Vita di Filipo Maria Visconti, iI3. Sobre el ajedrez y la política en el Renacimiento italiano véase Patricia Simons, "(Check) Mating the Grand Masters: The Gendered, Sexualized Politics of Chess in Renaissance Italy", Oxford Art Journal I6, núm. I (1993): 59-74. 
águilas, fénix y tortugas-, por el que pagó I 500 ducados. Berti y Marsili consideran que estas cartas pudieron haber estado relacionadas con figuras celebrativas, como la escena de caza de un juego de cartas alemán de principios del quattrocento, o con fines educativos como las cartas de Mantegna..$^{50}$ Este mazo fue denominado Triumphi. ${ }^{\text {sI }}$

\section{El tarot, la mnemotecnia y el neoplatonismo}

La práctica de la mnemotecnia en la corte de Filippo Maria Visconti pudo haberse visto alentada por la recepción de la obra de Petrarca (I304-I374) en la corte. Para 1388 Filippo Maria Visconti adquirió la biblioteca personal del poeta y la depositó en el castillo de Pavia. Es posible percibir la influencia de la obra del poeta en pinturas moralizantes, como el fresco Triumphus Cupidinis (probablemente de I445) pintado por Michelino da Besozzo (I370-I456) en una sala del Palacio Borromeo. ${ }^{52}$

En una de las mayores obras de Petrarca se encuentran los Triunfos. En estos versos, el autor narra los sucesivos triunfos del Amor, la Castidad, la Muerte, la Fama, el Tiempo y la Eternidad como valores en la vida de los hombres. ${ }^{53}$

Fabio Finotti considera que existe una relación entre la Divina Comedia de Dante y los Triunfos de Petrarca, pues ambas obras presentan una estructura vertical en la que, a manera de capítulos, cada escalón representa una victoria

50. Berti y Marsili, "La diffusione", io. En el museo de Stoccarda y en el Museo de Viena se conservan dos mazos iluminados incompletos con escenas de caza: el primero, renano de I430, era de 50 cartas donde las cuatro figuras son patos, halcones, perros y ciervos. El segundo, de originalmente 56 cartas, está dividido en cuatro figuras: de garzas, halcones, perros y aves, probablemente iluminado por Konrad Witz entre I44O-I445. Estos mazos hacen recordar el Ganjifa hindú, o el Kanjifah mameluco, en cuyas cartas se plasman elementos de la vida cotidiana y fueron usados con diversos fines marcados culturalmente.

5I. Andrea Vitali, "Ludus triomphorum e tarocchi", 9.

52. Véase Bandera, Brera, I tarocchi, I8. La aceptación de los Triunfos de Petrarca se extendió a diversas ciudades del norte de Italia. Así también en Florencia, Piero de Medici encargó a Mateo di Pasti una pintura de los Triunfos de Petrarca a mediados del siglo xv. Ernst H. Gombrich, Norma y forma, estudios sobre el arte del Renacimiento, trad. Santos Torroella (Madrid: Alianza Editorial, 1985), 90.

53. Véase Victoria Kirkham y Armando Maggi, Petrarch, a Critical Guide to the Complete Works (Londres-Chicago: The University of Chicago Press, 2009). Sobre los grabados que ilustraron los Triunfos en el siglo xv, Works of the Italian Engravers of the Fifteenth Century Reproduced in Facsimile by Photo-Intaglio, ed. George William Reid (Londres: Bernard Quaritch, I884), Q-X. 
y progresión moral sobre el anterior. ${ }^{54}$ Así, para Finotti los Triunfos de Petrarca son escalones en la vía del acercamiento a Dios, que el hombre debe recordar para poder mejorarse. En este proceso, la memoria es la base de la experiencia que ha de llevar a actos morales, como una condición necesaria para el arrepentimiento y la penitencia. Además, que la memoria histórica y literaria son las que le permiten al individuo "forjar su destino en la tierra, conformar su identidad individual y colectiva. 55 En suma, mediante la memoria el individuo rescata los valores de su experiencia terrenal del tiempo y por tal de la muerte.

Para Andrea Torre, la memoria de Petrarca marca el inicio de una experiencia educativa moral del individuo. ${ }^{56}$ Por su parte, Berti y Marsili trazan una relación entre los triunfos del tarot con los Triunfos de Petrarca. ${ }^{57}$ Ellos consideran que las cartas denominadas trionf $i$ cobraron ese nombre porque en el juego siempre vencen a las cartas numerales, las cuales tienen menor valor; ${ }^{58}$ piensan que estas cartas alegóricas pudieron haber tenido diversas fuentes de inspira-

54. "Del Triumphus Cupidinis (triunfo de El Amor) él llega al Triumphus Pudicitie (triunfo La Prudencia) y así sucesivamente hasta que llega al destino de su ascenso, el Triumphus Eternitatis (triunfo La Eternidad). En la conclusión del trabajo, el autor mismo establece el título y el número de triunfos, así como su curso de la tierra al cielo", en Fabio Finotti, "The Poem of Memory: Triumphi", en Petrarch, A Critical Guide to the Complete Works, eds. Victoria Kirkham y Armando Maggi (The University of Chicago Press, 2009), 63.

55. Finotti, "The Poem of Memory", 83. Idea que Finotti rescata de Petrarca: "Ea est rerum conditio humanarum, ut qui pauciora meminerit, minor illi fletuum causa sit. Ubi nec emendatio, nec penitentia utilis locum habet, quid superest aliud quam oblivionis auxilium?”, en Francesco Petrarca, De remedis utriusque fortune, citado en Finotti, "The Poem of Memory", 83.

56. Según esta autora la experiencia que propone Petrarca es por tanto una acción conjunta de ojos, mano y mente, una lucrativa interacción entre lectura, escritura y meditación, con el fin último de alcanzar la educación intelectual y la formación moral del individuo. Véase Andrea Torre, "Memoria e mnemotecnica nell'esperienza di lettura del Petrarca", Andrea Torre, Petrarcheschi segni di memoria. Spie, postille, metafore (Pisa: Edizioni della Normale, 2007), 77. Sobre Petrarca como poeta de la memoria véase Frances Yates, El arte de la memoria, trad. Ignacio Gómez de Liaño (Madrid: Siruela, 2005).

57. Para un estudio crítico de los Triunfos de Petrarca véase Carl Appel, Die Triumphe Francesco Petrarcas: in kritischen Texte (Halle: Max Niemayer, I90I).

58. La sucesión jerárquica de valores de los triunfos de Petrarca puede ser relacionada con los juegos de cartas triunfales como el Minchiate florentino o el Tarocchino de Bolonia, los cuales se norman de acuerdo con el orden de triunfos. En sus "Triumphi, Petrarca describe las principales fuerzas que rigen a los individuos y les asigna un valor jerárquico ascendente: primero se encuentra el Amor al que vence la Castidad, después está la Muerte, derrotada por la Fama, misma que se ve afectada por el Tiempo; finalmente se eleva sobre todas las fuerzas la Eternidad divida. Véase Berti y Marsili, "La diffusione", I4. 
ción, y las identifican con los carros triunfales de las procesiones carnavalescas de la Edad Media ${ }^{59}$ y con los Triunfos de Francesco Petrarca en tanto que pudieron ser instrumentos de la práctica del arte de la memoria, ya que el contexto cultural en el que apareció el juego de los triunfos ofrece varias posibles fuentes de inspiración de origen filosófico neoplatónico y literario. Esto debido a la semejanza de las figuras contenidas en los triunfos con imágenes enciclopédicas, que recuerda el Ars memorandi medieval, donde cada imagen estaba cargada con un significado moral y espiritual que percibía el observador. ${ }^{60}$ Bandera considera que los triunfos del tarot están relacionados con los de Petrarca puesto que las virtudes que acompańan el triunfo de la Fama de Petrarca - Templanza, Fuerza y Justicia — están incluidas en los triunfos del tarot. ${ }^{61}$

Se sabe que los juegos ingeniosos fueron apreciados en las cortes del Renacimiento italiano temprano tanto por su valor mnemotécnico como por su enseñanza moral. ${ }^{62}$ La popularidad de los juegos de cartas en la corte, incluidos los varios que eran denominados tarochi, se hace manifiesta en los frescos de algunos palacios como el de Borromeo de Milán, o los del castillo de Pavia ${ }^{63}$ e Issiogne.

59. Berti y Marsili, "La diffusione".

6o. Berti y Marsili, "La diffusione", I4.

6I. Bandera, Brera, I tarocchi, I8.

62. En los juegos de cartas, la mnemotecnia auxiliada por las imágenes era la base para el desarrollo del juego, pues sentaba los valores y las reglas cuyo fin era la instrucción moral. Berti y Marsili mencionan algunos ejemplos de juegos mnemotécnicos desafortunadamente no conservados, pero registrados en el Inventario Rosselli, como el "tablero para el juego del Triunfo de Petrarca", el "juego de los apóstoles con nuestro Señor", un "juego de las siete virtudes”, un "juego de los planetas con sus hijos", e incluso un "juego con figuras de Dios y de los animales pintado por Filippo Maria Visconti” (Berti y Marsili, "La diffusione”, Io). Sobre juegos de enseñanza moralmnemotécnica, véase Uwe Westfehling, "'Tarocchi' Menschenwelt und Kosmos. Ladenspelder, Dürer und die 'Tarock-Karten des Mantegna', Wallraf-Richartz-Museum Köln, 9. Nov. 1988 bis 22. Jan. I989, catálogo de la exposición (Colonia: Wallraf-Richartz-Museum der Stadt Köln, 1988). También véase De Ludo Globi de Nicolás de Cusa, en donde inscribe hipóstasis neoplatónicas cuando dice que el universo surge de un punto, y la región más alejada de él es la más imperfecta. Nicolás de Cusa, El juego de las esferas, trad. y notas de Rafael Martínez (México: Universidad Nacional Autónoma de México-Facultad de Ciencias-Mathema, 1994). E incluso el ajedrez presente en España bajo el reinado del rey Alfonso X el Grande, de Castilla (I283). Véase el facsímil, Alfonso el Sabio, Juegos del ajedrez, dados y tablas (Madrid y Valencia: Patrimonio Nacional/Vincent García Editores/Ediciones Poniente, 1987).

63. Galeazzo Maria Visconti comisionó a Bonifacio Bembo de I468 a I47I para la decoración de la sala del castillo de Pavia, destruido en el asedio francés a principios del cinquecento. En él se 
En 1565 Francesco Piscina da Carmagnola publicó en Piamonte el Discorso sopra l'ordine delle figure dei Tarocchi, obra dedicada al significado filosófico de las figuras y de su orden según la presunta intención del inventor, a quien el autor refiere como "buen y fiel adepto de la fe católica y cristiana, pero aún más experto y excelente de las costumbres de la vida civil". ${ }^{64}$ Ahí dice que el tarot termina con el "paraíso celeste" representado en la carta de El Mundo, al cual llegan las almas beatas. Para ello, el autor ha hecho pintar antes a un ángel (en la carta El Juicio) que alegra con su canto a los espíritus benditos que con sus buenas obras han conseguido aquella felicísima y sempiterna quietud. ${ }^{65}$

La exposición anterior ejemplifica el camino del alma humana hacia la divinidad tal como lo propone el neoplatonismo. ${ }^{66}$ Según éste, el hombre debe ir de la materia al mundo, al alma universal, al intelecto para luego llegar al Uno (noûs). A grandes rasgos diré que para el neoplatonismo todos los elementos del universo se encuentran conectados en una organizada correspondencia de seres que va del nôेs - la unidad perfecta, origen del mundo- a las esferas celestes, y en última instancia a los seres humanos, animales, vegetales y minerales. ${ }^{67}$

Hay que recordar que el neoplatonismo que surgió en el siglo III con Plotino se desarrolló con diversos autores que, con una finalidad mística, retomaron sincréticamente elementos de Platón (427-347 a.C.), Pitágoras (s. vi a.C.), Orfeo, Zenón (490-430 a.C.), Aristóteles (384-322 a.C.), del estoicismo, así como también de Zoroastro (ca. siglo vir a.C.), de movimientos religiosos como la gnosis y el hermetismo, de los cultos mistéricos del mundo antiguo y de las doctrinas soteriológicas de Oriente, de lo que resultó una amplia variedad de interpretaciones y comentarios. ${ }^{68}$ En el Corpus hermeticum se identifica a Dios

representaría "la ilustrísima madona, Bona de Saboya, y la ilustrísima madona Isabela jugando con sus doncellas el triumphi, y se veía a Virgilio, don Biaso y Zohanne Antonio", en Bandera, Brera, I tarocchi, 17 .

64. "buono e fedel seguace della Catholica e Cristiana fede, ma etiandio molto esperto ed eccellente de i costumi della vita civile". Berti y Marsili, "La diffusione", I.

65. Berti y Marsili, "La diffusione".

66. Véase Thomas Taylor, Collected Writings of Plotinus (Somerset: Prometheus Trust, 1994); Pietro Prini, Il Neoplatonismo nel Rinascimento (Roma: Istituto della Enciclopedia Italiana, 1993); Juan Cruz Cruz, Neoplatonismo y mistica: la contemplación en la obra de Tomás de Jesús (s. XVI) (Pamplona: EUNSA, 20I3).

67. Véase Marsilio Ficino, Theologia platonica de immortalitate animorum, trad. Raymond Marcel (París: Société d’Édition Les Belles Lettres, 1964); Marsilio Ficino, Mercurii Trismegisti Liber de potestate et sapientia dei: Pimander: Corpus Hermeticum I-XIV (Florencia: SPES, I989).

68. Véase una compacta exposición en José Alsina Clota, El neoplatonismo: sintesis del espiri- 
con el bien; el hombre debe llegar a ser consciente de que el objetivo de su vida es regresar a la divinidad, con lo cual se vuelve divino a sí mismo. Para ello, hay que purificarse de los verdugos de uno mismo. ${ }^{69}$ La purificación se logra por medio de Io remedios o potencias: "hay que ir oponiendo diez potencias: conocimiento de dios, alegría, continencia, perseverancia, justicia, generosidad, verdad". ${ }^{70}$

\section{El triunfo de El Mago}

Una vez esbozado el contexto cultural en el cual se jugaba al tarot, dirigiré mi atención a la carta del triunfo del Mago. Este triunfo es nombrado como bagattella en el siglo $\mathrm{XV}^{71}$ y como giocoliere en el siglo XVI (fig. I). ${ }^{72}$ El Mago probablemente se representó con una imagen consistente en los tres mazos visconteos, ${ }^{73}$ se trata de un hombre rubio con barba, vestido de rojo y sentado sobre un cubo dorado. En la mano izquierda sostiene una vara. Frente a él se encuentra una mesa sobre la cual están dispuestos, de izquierda a derecha: un cuchillo, un par de objetos que podrían considerarse dos pequeñas piedras, lo que parece ser un vaso, y un objeto blanco indefinible dispuesto de forma redonda.

tualismo antiguo (Barcelona: Anthropos, 1989). Este sistema filosófico se extendió en Occidente especialmente después de las traducciones que desarrolló Marsilio Ficino en Florencia durante la segunda mitad del siglo xv. Mas al respecto del neoplatonismo en el humanismo italiano del Renacimiento véase Amos Edelheit, Ficino, Pico and Savonarola: the Evolution of Humanist Theology I46I-I498 (Leiden: Brill, 2008); The Perennial Tradition of Neoplatonism, ed. John J. Cleary (Leuven University Press, 1997); Neoplatonism and the Philosophy of Nature, eds. James Wilberding y Christoph Horn (Oxford University Press, 2012); Neoplatonism and Gnosticism, eds. Richard T. Walls y Jay Bregman (Albany: State University of New York Press, 1992).

69. "Este desconocimiento, hijo mío, es el primer tormento; el segundo es la tristeza; el tercero la incontinencia; el cuarto, la lujuria; el quinto, la injusticia; el sexto, la avaricia; el séptimo, la mentira; el octavo, la envidia; el noveno, el fraude; el décimo, la cólera; el undécimo, la precipitación; el duodécimo, la malicia. Éstos suman doce en total, pero detrás de ellos se esconden muchos, hijo mío, que utilizan la prisión del cuerpo para atormentar a la persona interior con los sufrimientos de los sentidos", en Corpus hermeticum y Asclepio, ed. Brian P. Copenhaver, trads. Jaume Pòrtulas y Cristina Serna (Madrid: Siruela, 2000), I27-I28.

70. Corpus hermeticum y Asclepio, I73.

71. Steele, A Notice of the Ludus Triumphorum, 2.

72. Berti y Marsili, "La diffusione", II.

73. Para este análisis me basé en El Mago del tarot Visconti-Sforza. 
Este sujeto era llamado el "jugador" porque representa a un hombre al lado de una mesa, con lo que parecen los utensilios necesarios para los juegos de cubilete. También era llamado bagatela porque como prestidigitador engañaba a la vista con la manipulación de su utilería, y lograba muchas veces la pérdida de dinero del espectador. La bagatela, por ser un juego de azar, estaba prohibido por la Iglesia. ${ }^{74}$

Sin embargo, gracias a la iconografía de la imagen de El Mago es posible aproximarse a una interpretación diferente. Vettius Valens (I2O-I75 a.C.) en sus Anthologiarum libri habla de la influencia planetaria en la vida de los hombres. Consideraba las características del planeta regente de la fecha en que había nacido la persona para establecer correspondientemente las que dicha persona habría de tener, entonces como "hijo" del planeta. Éstas comprendían la fisiognomía y la caracterología con las específicas cualidades planetarias. A decir de Lippman:

Pero el influjo de los Planetas cambiaba según la Constelación en la que se encuentre. En algunas constelaciones tiene el planeta su poder más alto o exaltado, en otro su menor [poder] o en degradación [retroceso]. En una o en dos constelaciones tiene el planeta su casa o su vivienda. [...] Sobre el complicado rumbo de las conclusiones astrológicas se construye un sistema, que concede un conjunto de cualidades a cada planeta, que en lo fundamental se basan en la mayor o menor malinterpretación del carácter de las deidades antiguas [...] él tenía otros planetas para enemistar o amistar, que luego otra vez, según su lugar en las Constelaciones, fortalecía su poder o lo debilitaba. Pero sobre todo, el planeta ejerce su influjo sobre la vida de los hombres que nacen al momento de su camino sobre las diferentes constelaciones, en efectividad afín. Estos hombres son los hijos de los planetas, su carácter y sus ocupaciones, las cuales persiguen con predilección, así se formarán, como el planeta comanda e implica. ${ }^{75}$

74. Steele, A Notice of the Ludus Triumphorum, 2.

75. "Aber der Einfluss eines Planeten wechselt je nach dem Sternbild; in dem er steht. In gewissen Sternbildern hat der Planet seine höchste Kraft oder Erhöhung, in anderen seine geringste oder Erniedrigung. In einem oder in zwei Sternbildern hat der Planet sein Haus oder seine Wohnung. [...] Auf den komplizierten Pfaden der astrologischen Schlussfolgerung bildete sich ein System heraus, dass jedem Planeten eine Menge Eigenschaften erteilt, die in der Hauptsache auf dem mehr oder minder missverstandenen Charakter der antiken Gottheiten fussen. [...] er hat andere Planeten zu Feinden oder zu Freunden, die dann wieder, je nach ihrer Stellung in den Sternbildern, seine Macht stärken oder schwächen. Vor allem aber übt der Planet seinen Einfluss 
DOI: http://dx.doi.org/10.22201/iie.18703062e.2018.112.2635

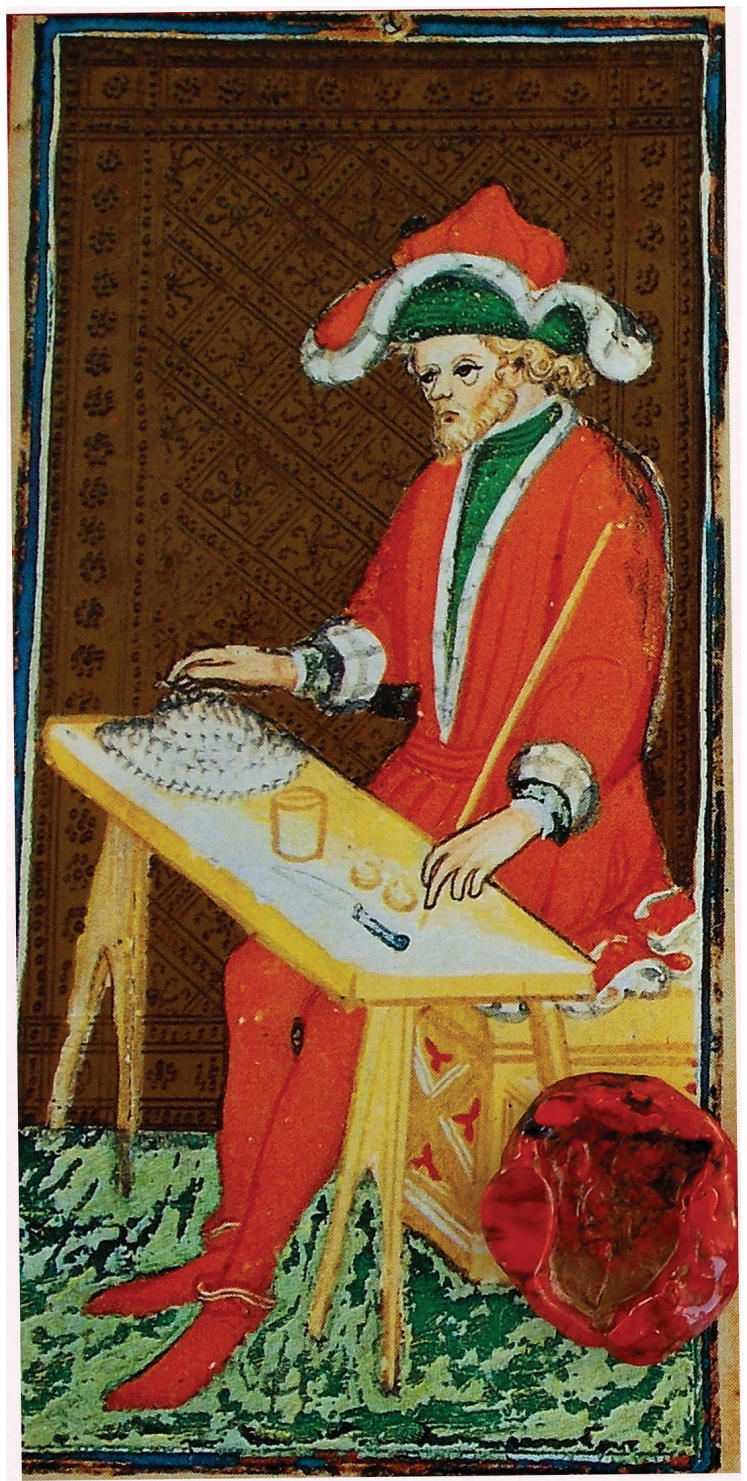

I. Bonifacio Bembo, El Mago del tarot Visconti, Italia, ca. I447-I477, miniatura con taroccato. Visconti-Sforza Tarot Cards. The Morgan Library and Museum, MS M.630.I. 
En el grabado de los hijos de la Luna se representa a un prestidigitador. Tiene en su mesita los elementos para realizar su acto performativo, dados y cubilete (fig. 2). ${ }^{76}$ Según el Picatrix, tratado de magia astrológica o talismánica escrito en Espańa alrededor del siglo xi y ampliamente difundido a lo largo de la Edad Media, 77 la Luna imprime en sus hijos cualidades intelectuales para la geometría y la aritmética, la nigromancia, la medicina y la investigación de las cosas de los antiguos, como la fabricación y uso de ídolos y los talismanes (fig. 3). Dice:

La Luna es quien recibe las virtudes planetarias y las infunde en el mundo, y es mineral de la virtud natural. Y tiene influencia sobre la geometría y la aritmética, y sobre el curso del agua por peso y por medida, y las altas ciencias, la nigromancia y la física y peticiones de cosas antiguas [...] y por leyes a quienes invocan a ídolos e imágenes; $y$ de entre las piedras las perlas pequeñas; $y$ de entre los metales la plata $\mathrm{y}$ aquellos que tienen cuerpo blanco. ${ }^{78}$

El Mago hijo de Venus se representa como prestidigitador que engaña por su rápido movimiento de manos, y crea imágenes que atentan contra la realidad establecida. Puede establecerse en analogía que el fabricante de talismanes, a fin de atraer la influencia astral al mundo terrenal, atenta también contra el curso establecido. El Mago se convierte en aquella persona que al crear imáge-

auf die Menschen aus, die in den Zeiten seiner durch die verschiedenen Konstellationen bedingten Wirksamkeit geboren sind. Diese Menschen sind die Kinder des Planeten, ihr Charakter und die Beschäftigung, der sie mit Vorliebe nachgehen, wird sich so gestalten, wie es der Planet gebietet und mit sich bringt", en Friedrich Lippman, Die sieben Planeten (Berlín y Nueva York: Amsler \& Ruthardt-H. Wunderlich, I895), I.

76. La figura 2 proviene de "Luna und ihre Kinder", Mittelalterliches Hausbuch von Schloss Wolfegg (ca. I475-I500), consultada en la Photographic Collection Warburg Institute. Existen abundantes representaciones del prestidigitador, tal vez una de las más célebres sea la de SaintGermain-en-Leye (De goochelaar, ca. I475-1500), sin embargo, en el presente estudio me enfoco en las que presentan contenido astrológico.

77. David Pingree, "Some of the Sources of the Ghāyat al-hakī", Journal of the Warburg and Courtauld Institutes, vol. 43 (1980): I-I5.

78. "Luna est que recipit virtutes planetarum et infundit eas in mundo, et est minera virtutis naturalis. Et habet aspectum ad geometriam et aristmetricam, et in concursibus aquarum pondere et mensura, et altas sciencias, nigromanciam et phisicam et peticiones earum et rerum antiquarum [...] et ex legibus idola orantes et ymagines; et ex lapidibus perlas minutas; et ex metallis argentum et ea que corpora alba habent", Picatrix: the Latin version of the Ghayat al-hakim, ed. David Pingree (Londres: The Warburg Institute, 1986). También véase Picatrix. Un traité de magie médiéval, eds. Béatrice Bakhouche, Frédéric Fauquier y Brigitte Pérez-Jean (Turnhourt: Brepols, 2003). 


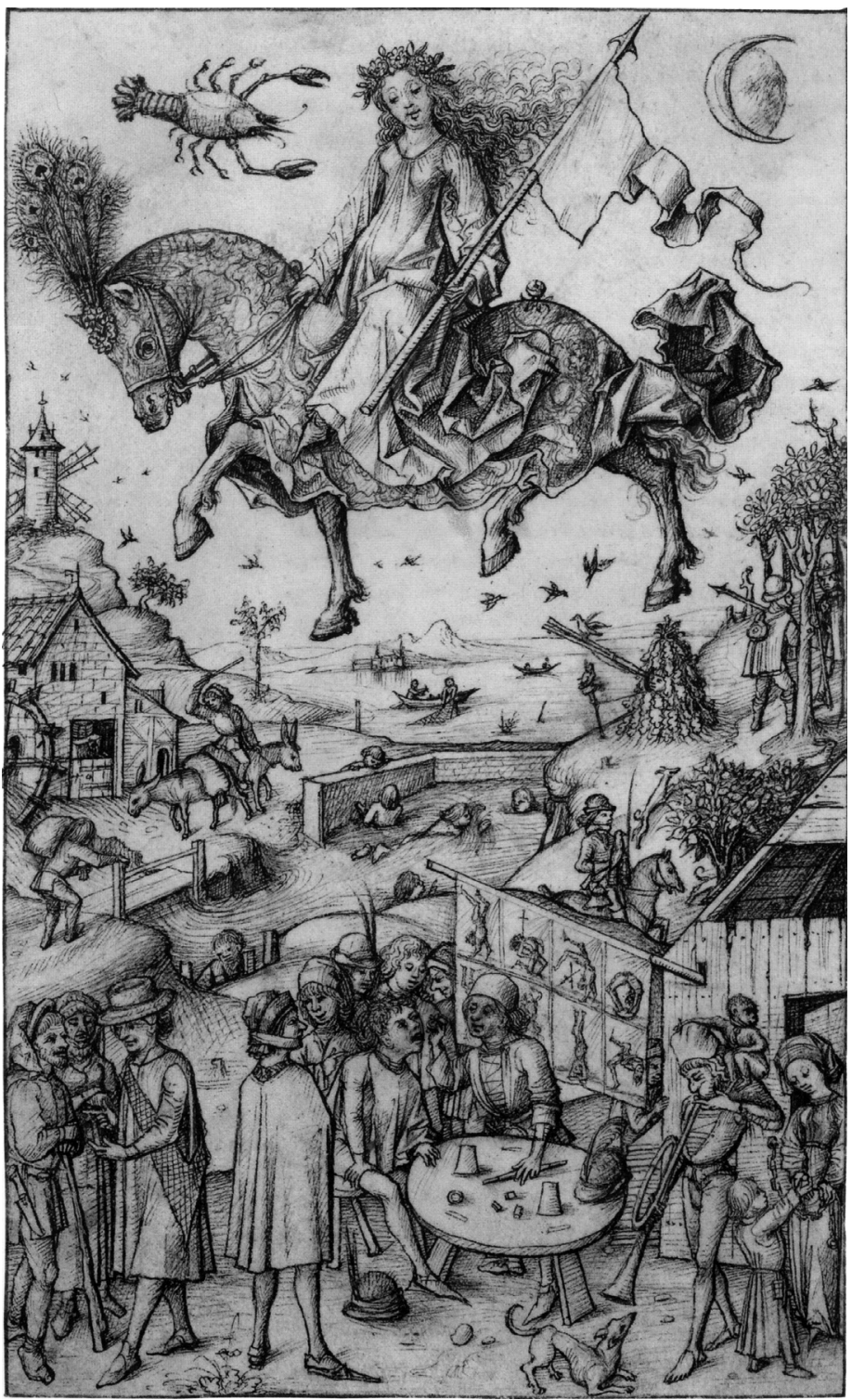

2. Autor desconocido de los Países Bajos, Los hijos de la Luna (Die sieben Planeten), siglo xv, grabado en madera, en Das Mittelalterliche Hausbuch, eds. Helmuth Th. Bossert y Willy F. Storck (Leipzig: I9I2), placa I8. Colección Fotográfica del Warburg Institute. 
nes tiende un puente entre la suposición normal de la existencia y la esfera de las posibilidades.

Paolo Aldo Rossi, al analizar el papel práctico de la magia en el Renacimiento italiano, considera que el Mago es el hombre consciente de las capacidades de la filosofía natural, y aplica las empíricamente comprobadas potencias naturales con fines prácticos. ${ }^{79}$

Por lo general este tipo de potencias naturales estaba relacionado con la influencia de los astros en la vida del hombre, idea que generaba grandes polémicas entre los hombres del Renacimiento, quienes intentaron aprovechar su funcionalidad, ${ }^{80}$ y explicar en un sentido filosófico la coexistencia tanto de las fuerzas naturales en el hombre, como el libre arbitrio humano frente a los designios divinos. ${ }^{8 \mathrm{I}}$

79. Dice que el amor por el saber hace al Mago consciente de que el conocimiento es la vía para romper el círculo ineludible del destino, el cual se encuentra escrito en los cielos y cuyos mensajeros son los astros. Para Rossi, el Mago, de acuerdo con el Picatrix, es la persona capaz de seguir el intrincado conjunto de hilos entre la tierra y el cielo, y con ello puede conocer el mundo natural, e incluso operar sobre él, a decir de Pico della Mirandola en su XIII Conclusiones magicae. Para Rossi, se trata de la operación demiúrgica de Trismegisto (de la que habla el Pimandro) donde el Mago es investido por los poderes, inscrito en la naturaleza del todo y hecho partícipe de la visión suprema. Véase Paolo Aldo Rossi, “Il 'Gioco' dei tarocchi fra 'eremitismo' e 'Teatro della memoria”, en Tarocchi le carte del regno, la storia, i simboli, il mito, eds. Andrea Ascari, Giordano Berti y Andrea Vitali (Milán: Edizioni Le Tarot, 1997), 55-66. Para Kieckhefer la forma de diferenciar la magia natural de la demoniaca radica en que la primera se consideró incluso en el medioevo en muchas ocasiones sospechosa debido a la poca claridad en sus mecanismos de operación empírica; mientras que la segunda se caracterizó por su pragmatismo y poder de eficacia, aspectos que fomentaron mayor conciencia en los individuos, véase Richard Kieckhefer, Forbidden Rites, a Necromancer's Manual of the Fifteenth Century (Stroud: Sutton Publishing, 1997), 12. La necromancia muchas veces se asimiló como la práctica de invocar a un demonio o al espíritu de un muerto para llevar a cabo algún fin o recibir un augurio.

80. Como se enseña en el quadrivium, y cuyas finalidades prácticas se encuentran en tratados médicos, como el manuscrito francés del siglo XIII (facsímil, Colección Fotográfica del Warburg Institute, ms O.I.20); y en la obra de Alberto Magno (Albertus Magnus, Liber de virtutibus herbarum, lapidum et animalium, ed. Isabelle Draelants [Florencia: sismel-Edizioni del Galluzzo, 2007]).

8I. Véase Lettere, ed. Sebastiano Gentile [Florencia: L.S. Olschki, 20Io]. Por su parte, Ficino en sus Lettere no pudo rebatir las acusaciones de nigromancia realizadas por Savonarola. Véase Girolamo Savonarola, Contro gli astrologi, ed. Claudio Gigante (Roma: Salerno Editrice, 2000). También Pico della Mirandola en: Giovanni Pico della Mirandola, Conclusioni ermetiche, magiche e orfiche, ed. Paolo Edoardo Fornaciari (Milán: Mimesis, 2003); y Disputationes adversus astrologiam divinatricem, ed. Eugenio Garin (Florencia: Vallecchi, 1946). 
3. Autor alemán desconocido,

Prestidigitador hijo de la Luna, grabado,

ca. I450. Planetas representados como deidades planetarias en (adaptación irregular alemana del) Miguel Escoto, Liber Introductorius (Berlín: Staatsbibliothek, $c a$. I450) germ. fol. 244, fol. I9or. Colección fotográfica del Hamburg Stamp, Biblioteca del

Warburg Institute.

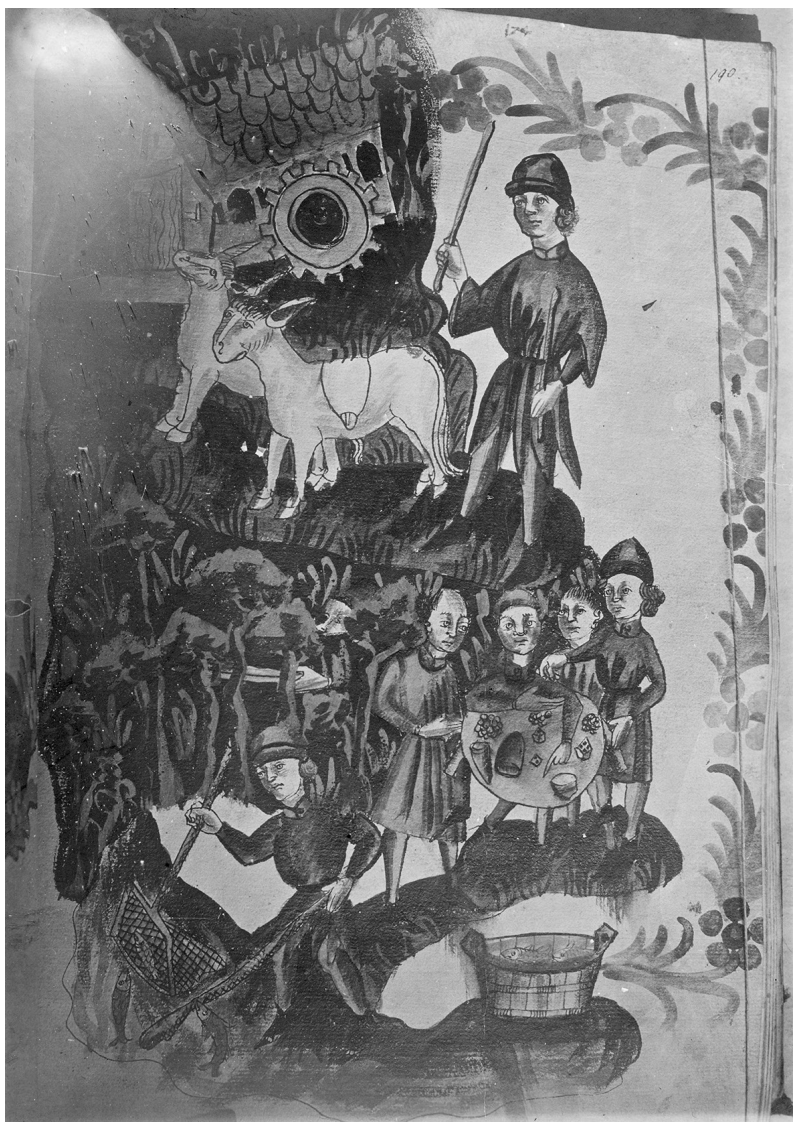

La magia dentro de la fe cristiana sólo es aceptada bajo el nombre de milagro, y en la Biblia la practican los personajes ejemplares de Moisés y Jesús. Todo otro uso de magia está condenado por ser considerado hechicería o adivinación. Sin embargo, en el Salmo 58, Clamor de justicia, el suplicante pide a Dios justicia en contra de los poderosos malintencionados que causan violencia. Según el Salmo, estos malvados están "pervertidos desde el vientre y son como víboras venenosas que se hacen las sordas para no oír la música del Mago, del experto en encantamientos". ${ }^{82}$

82. Salmo 58:5 (La Biblia, versión popular, Dios habla hoy [Bungay: Richard Clay The Chaucer Press, 1979]), 695 . 
La cita anterior sugiere la relación de la música con la armonía; El Mago como productor de la misma sería el responsable de encantar al malvado encaminándolo al bien. ${ }^{83}$ En este sentido, la figura del Mago se presenta como buena en tanto que por medio de la música — y de sus sortilegios— rompe el esquema del vicio elevando al malo a un estado de bondad, aunque en la descripción anterior, El Mago fue incapaz de hacerse escuchar para transformar el grado de maledicencia de los poderosos. Durante la Edad Media, se consideraba que los ermitańos eran santos con dones teúrgicos. ${ }^{84}$

Sin embargo, los elementos que tiene en su mesa El Mago no se limitan sólo a una pelota y a un cubilete, como se muestran en la iconografía del prestidigitador hijo de Venus. En una copia del Liber introductorius de Miguel Escoto

83. La armonía representada iconográficamente con dioses grecorromanos fue muy difundida en el Renacimiento italiano, como lo explica Warburg al dar cuenta de su personificación bastante difundida, pues se encuentra por ejemplo en los grabados del denominado tarot de Baldini, y en la Harmonia Musicorum Instrumentorum de Gafurius, donde se puede apreciar una xilografía con Apolo entronizado, desde cuyos pies desciende una sinuosa serpiente cuya triple cabeza toca la tierra. Sobre la espalda de la serpiente, los nombres griegos de los modos forman las ocho cuerdas de la lira, y en los extremos de las cuerdas hay unos medallones circulares: a la derecha, las musas y, a la izquierda, los planetas; a la derecha de Apolo están las Gracias y sobre él pueden leerse las siguientes palabras: Mentis Apollineae vis has movet undique musas (la fuerza de la mente de Apolo mueve las musas por todos lados). Véase Aby Warburg, "El vestuario de los intermezzi de I589 (I895)", en Warburg, El renacimiento del paganismo, 299.

84. Heribert Rosweyde, Vitae Patrum, De vita et verbis (Amberes: Ex Officina Plantiniana: apud viduam et filios Jo. Moreti, I6I5), consultado el 2 de julio de 20I5, en https://archive.org/ details/VitaePatrumRosweyder6ı5. Véase Andrea Vitali, “Trionfi, trionfini e trionfetti”. Existe además una relación entre santidad, ayuno y limpieza con la realización de ritos mágicos (Picatrix: the Latin Version of the Ghayat Al-hakim, 53). También se han encontrado textos mágicos en manuscritos del alto clero (Kieckhefer, Forbidden Rites, 4). Claire Fanger en su estudio de la magia ritual en el Renacimiento, puntualiza que la alta magia (learned magic) "problemática o no, se encontraba en manos de una élite intelectual que también estaba involucrada en el discurso teológico" "[problematically or not] the province of the intellectual elite who were also involved in theological discourse", y que la magia, si bien fuera de los límites de la legitimidad eclesiástica, escapó de las estructuras disciplinarias: "uno de los muchos cargos asestados contra ella, empezando por parte de los Padres de la Iglesia, fue que no constituía un conocimiento real; propiamente no pertenecía al conocimiento teológico ni al curricular, y estaba conectado más bien con la superstición y con la curiosidad dañina" "One of the many charges leveled against in from the Church Fathers onward was that it did not constitute real knowledge; it did not properly belong either to theological or curricular knowledge, and was connected rather to superstition and harmful curiosity", en Claire Fanger, "Christian Ritual Magic in the Middle Ages", History Compass II, núm. 8 (agosto, 20I3): 6II. 
— de la segunda mitad del siglo XIV— ${ }^{85}$ se representa a Saturno, Júpiter, Marte, Venus y Mercurio. La imagen de Júpiter es muy parecida a la del Mago del tarot visconteo. En la mesa de Júpiter se encuentran tres de los cuatro tipos de elementos presentes en la mesa del triunfo del Mago. ${ }^{86} \mathrm{El}$ texto que enmarca la imagen describe la influencia benigna que Júpiter tiene sobre sus hijos:

Aquí Júpiter quien fija el buen augurio que tienen los nacidos bajo su tránsito. Él por su birreta indica la buena fortuna, fama, esperanza y paz. Júpiter busca un buen estatus, siempre es una influencia noble. La ramilla indica también dignidad (mérito, prestigio) y mucha habilidad para ser el jefe de las personas. Causa guerra cruel y destructora. Indica, al mirar a la derecha, que escoge juicios hacia el bien. Los guantes que tiene en la mano indican la consolación del vino. La bolsa (de reserva) indica riqueza temporal que siempre tienen los nacidos bajo la indefectible estrella. Entre los que no caen [ilegible] y que son de aspecto amable (atractivo) a toda persona en cada etapa de su vida hasta el momento en que ésta se extingue. ${ }^{87}$

Entre la descripción de su simbología poca mención hace a los elementos de la mesa, sin embargo, el texto habla de una virga, cuya traducción es una ramilla - como aparece representada en el manuscrito- aunque también puede ser una varilla, un bastón o una asta. Al regresar al triunfo de El Mago, es posible observar cómo éste sostiene una vara en la mano izquierda. ${ }^{88}$

Los mismos elementos aparecen en el grabado del siglo Xvi de Achille Bocchi (I488-I562), symbolon II8 (fig. 4), que lleva por título la máxima de Horacio (65-8 a.C.) Sperne voluptates. Nocet empta dolore voluptas. ${ }^{89} \mathrm{El}$ symbolon incluye un grabado donde se representa una mesa con varios comensales departiendo. En el centro de la misma, se observan un mazo, una daga y un plato de contenido irreconocible - parecido al presente en el triunfo del Mago. ${ }^{90} \mathrm{El}$ tex-

85. Colección Fotográfica del Warburg Institute. Miguel Escoto, Liber Introductorius, facsímil (Padua, siglo xIv).

86. Colección Fotográfica del Warburg Institute, consultada el 2 de julio de 20I5, en http:// iconographic.warburg.sas.ac.uk/vpc/VPC_search/pdf_alternative.php?image=00015158.

87. Colección Fotográfica del Warburg Institute.

88. La misma observación puede hacerse incluso con el triunfo de El Carro y El Ermitaño.

89. "Perjudica el placer comprado con el dolor", en Eclogae Horatianae, Pars II. Sermones Prope Omnes Continens, addita est Familiaris Interpretatio Orellii, ed. Thomas Kerchever Arnold (Londres: Rivington, I843), 50.

90. El symbolon es un signo icónico que refiere a la noción de hieroglíficos, como eran considerados en el Renacimiento, es decir, como signo sagrado cuya interpretación requiere conocimiento 
to de Horacio es un llamado a gobernar el corazón usando la razón, así como dominar y reprimir los apetitos y los deseos. Otro grabado de Bocchi, el symbolon 27 (fig. 5), expresa una idea similar, que el hombre que quiera ser digno de Dios no debe ser guiado por las necesidades de la tierra, sino por la palabra de Dios. En este grabado hay dos mujeres, con vestidura ligera que presentan la placa, con la leyenda escrita en griego, a un hombre que parece estar llevándose algo a la boca con la mano izquierda; él está sentado en una mesa cubierta con un mantel. Sobre la mesa se encuentra, del lado izquierdo, lo que parece ser una lámpara y un plato; cerca de la mano derecha hay dos elementos esféricos de mayor tamaño que el otro par que se encuentra cerca del antebrazo derecho, también se ve un cuchillo y un modelo triangular sobre una base cuadrada. Los elementos sobre la mesa no dejan de recordar a los representados en la carta del Mago.

Otro grabado en el que se puede observar una mesa compuesta de manera similar, es el de Filemón y Baucis del siglo XvII. ${ }^{\text {II }}$ En esta pieza se ejemplifica la hospitalidad del par, que compartió su alimento con los dioses Zeus y Mercurio, quienes acudieron a su casa disfrazados de mendigos. Se observa sobre la mesa algo de comida, un cuchillo, un par de pedazos de tela y una figura geométrica, rectangular. Este grabado se integró después a diversas ediciones del siglo XviII de las Metamorfosis de Ovidio (43 a.C.-I7) (fig. 6), ${ }^{92}$ tanto por hacer referencia a la metamorfosis de los cuerpos con los que Zeus y Mercurio se presentaron a Filemón y a Baucis, como por la recepción que Ovidio, poeta del amor y la transformación, tuvo desde el medioevo, como base para la

esotérico específico. Los symbola están compuestos por una quaestio que le da nombre; un epigrama que describe el objeto y sus características enigmáticas, y un grabado. El grabado es una ilustración y explota estrictamente la narrativa o los elementos icónicos del texto: el objeto simbólico, la alegoría y el elemento comparativo de la metáfora, aunque la inclusión de los elementos icónicos es selectiva. A veces el grabado también presenta interpretaciones de los textos, por lo que para dilucidar el significado de los symbola se requiere un amplio conocimiento de la antigüedad clásica, la psicología y la cultura de la época, que constituyen las fuentes que Bocchi juxtapone. Anne Rolet, "Achille Bocchi's Symbolicae Quaestiones", en Mundus Emblematicus Studies in NeoLatin Emblem Books, vol. IV, eds. Karl Enenkel y Arnoud Visser (Thurnhout: Brepols, 2003), iI5.

9I. Otto van Veen, Quinti Horatii Flacci Emblemata (Amberes: Ex Officina Hieronymi Verdussen, I607).

92. Este grabado se utilizó luego en Ovidio, Les Metamorphoses d'Ovide en latin et français (Ámsterdam: Chez P. et J. Blaeu, Janssons à Waesberge, Boom et Goethals, I702), 264. La edición de 1702 incluye grabados holandeses y flamencos, algunos de los cuales vieron la luz a principios de I600 y otros en la edición de I677. 
DOI: http://dx.doi.org/10.22201/iie.18703062e.2018.112.2635

MODELOS DE LA IMAGEN

\section{cCXIVIII LIB. IIII. \\ SPERNE VOLVPTATES \\ NOCET EMPTA DOLORE VOLVPTAS.}

\section{Symb. CXVIII.}

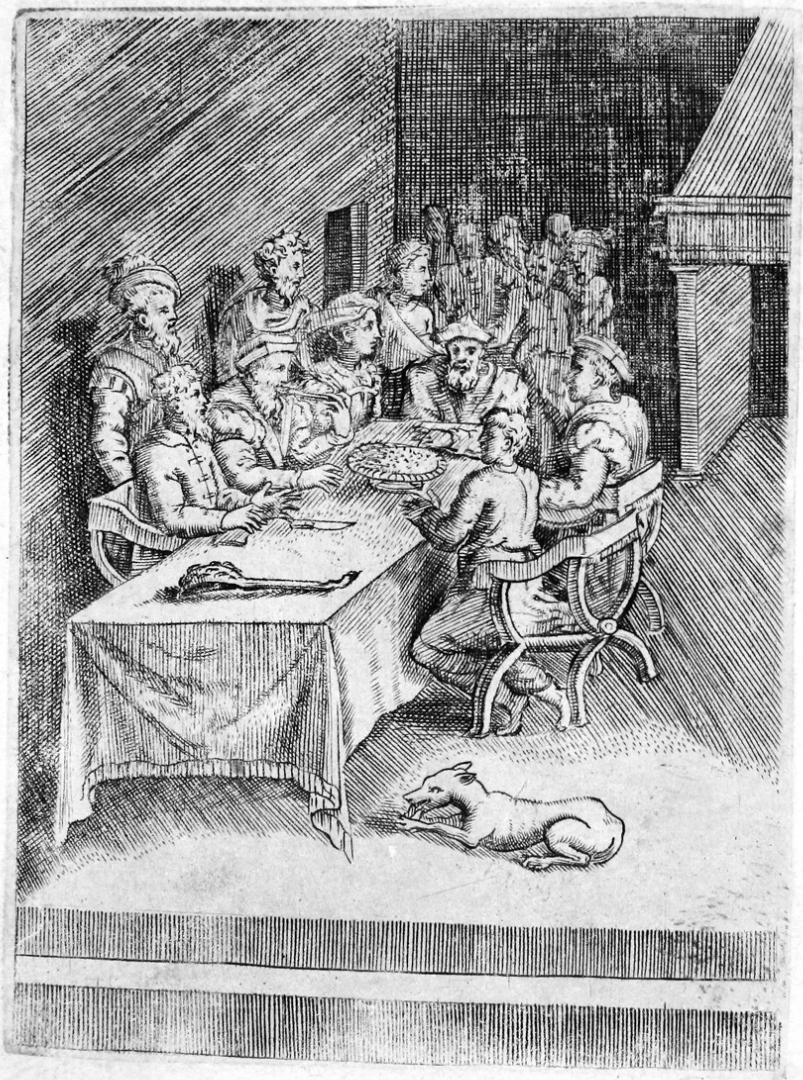

4. Giulio Bonasone, Symbolon CXVIII: Sperne voluptates. Nocet empta dolore voluptas, Bolońa, I574, grabado tomado de Achille Bocchi, Symbolicarum quaestionum, de universo genere, quas serio ludebat, libri quinque, lib. IIII (Boloña: Apud Societatem Typographiae Bononiensis, 1574), 248. Colección Fotográfica del Warburg Institute. 
DOI: http://dx.doi.org/10.22201/iie.18703062e.2018.112.2635

I64

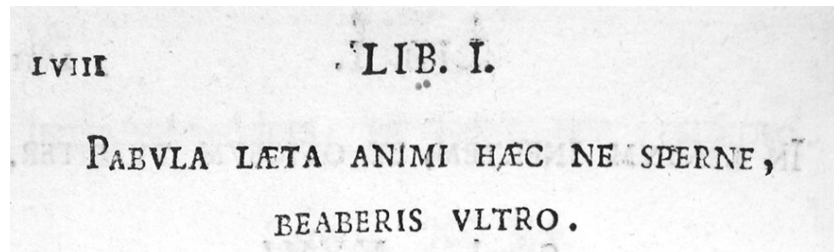

HOC ILLVD BOCCHI NOBILE SYMPOSIVM EST.

\section{Symb. XXVII.}

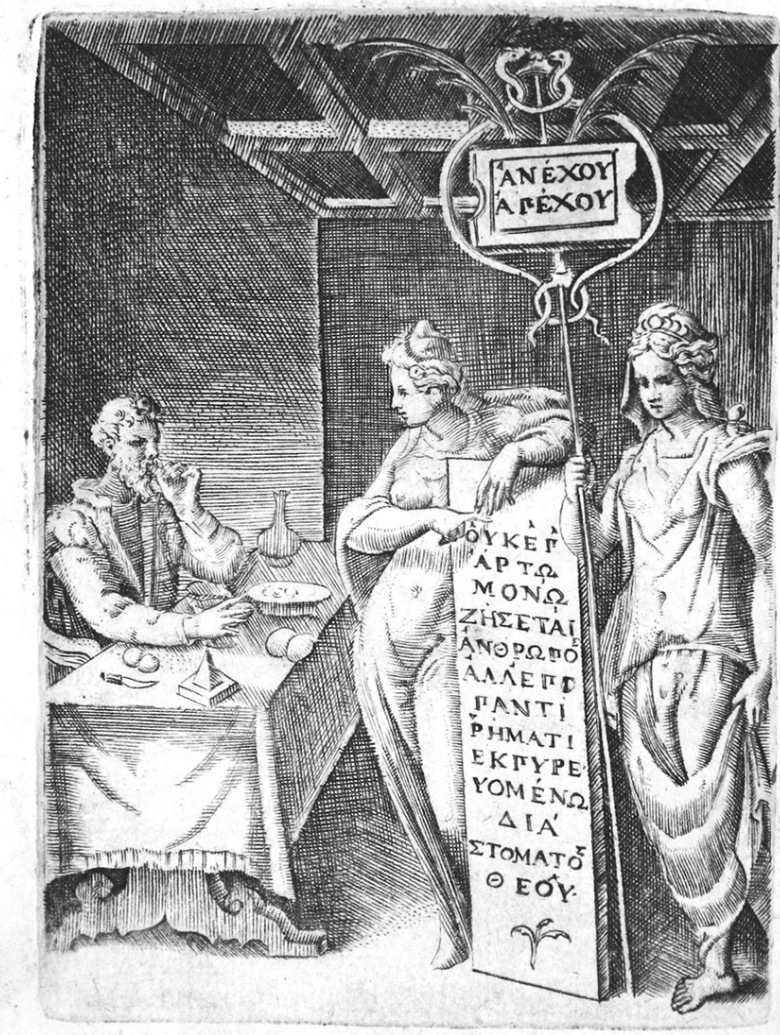

5. Giulio Bonasone, Symbolon XXVII: Pabula loeta animi hoec ne sperne, beaberis vltro, Bolońa, 1574, grabado tomado de Achille Bocchi, Symbolicarum quaestionum, de universo genere, quas serio ludebat, libri quinque, lib. I (Bolońa: Apud Societatem Typographiae Bononiensis, I574), 58. Colección Fotográfica del Warburg Institute. 
interpretación alquímica. ${ }^{93}$ Según lo explica Thomas Willard, las Metamorfosis resultaban una buena guía para los procesos alquímicos, puesto que tradicionalmente los metales obtenían los nombres de diversos dioses grecorromanos. ${ }^{94}$ Cabe recordar en este punto que la acepción neoplatónica de los planetas como daemones, con regencia sobre los elementos que se consideran creados por ellos, abre la posibilidad de una magia talismánica, es decir, de la práctica de dirigir invocaciones a algún daemon utilizando talismanes del mineral con el que éste tiene simpatía y sobre el que ejerce mayor poder.95

El doble aspecto de los planetas, sensible e inteligible, se transmite también a la naturaleza bajo su jurisdicción, ${ }^{96}$ de tal forma que la práctica de la alqui-

93. Sobre la etimología antigua del término alquimia véase Charles Burnett, "The Astrologer's Assay of the Alchemist: Early References to Alchemy in Arabic and Latin Texts", en Charles Burnett, Magic and Divination in the Middle Ages. Texts and Techniques in the Islamic and Christian Worlds (Norfolk: Variorum, 1996), I04.

94. Willard, "The Metamorphosis of Metals", I5I.

95. De acuerdo con el manual talismánico Picatrix: "Aristóteles dijo en otro lado que cualquier sabio tiene una fuerza propia influida por una alta espiritualidad, la cual le fortalece y le abre las puertas cerradas de la percepción y el intelecto, y le da a conocer la ciencia. Y este poder está ligado con el poder del planeta dominante en origen del nacimiento, tal poder entonces concreado consigo mismo se refuerza y se brinda intelecto a sí mismo. Los sabios y reyes antiguos solían hacer este trabajo y de esta forma, oraban diciendo oraciones con cuatro nombres, las cuales ayudaban en sus ciencias e intelectos y aumentaban sus negocios y cosas, y desde estos se defendían a sí mismos de las acechanzas de enemigos, y hacían muchas otras [cosas]. Que también Aristóteles dijo que el primero que fue trabajado con imágenes y cuyos espíritus aparecieron primero fue Caraphzebiz." ("Aristoteles autem ait quod unusquisque sapiens habet virtutem propriam sibi a spiritibus altis infusam, quibus potenciis clausure sensus et intellectus aperiuntur et sciencie patefiunt. Et hec virtus cum virtute planete dominantis in radice nativitatis coniungitur, que virtus sic secum concreata ipsum roborat et sibi dat intellectum. Sapientes quidem antiqui et reges hoc opus facere solebant et hac oracione cum quatuor nominibus supradictis orabant, quibus se iuvabant in suis scienciis et intellectibus et augmentacionibus suorum negociorum et rerum, et ex istis se tuebantur ab insidiis inimicorum, et multa alia faciebant. Qui eciam Aristoteles dixit quod primus qui fuit cum ymaginibus operatus et cui spiritus primo apparuere fuit Caraphzebiz"), en Picatrix: the Latin Version of the Ghayat al-hakim, III.

96. Por ejemplo: "Saturno es fuente [...] de las gémas, el ónice, la piedra negra y el imán; de los minerales, el plomo, el hierro y todos los de color negro y olor a podrido [...]. Júpiter [...] De los minerales son suyos el escańo y el cinc; de las plantas el nogal, el almendro [...] Marte [...] de los oficios la forja del hierro, el trabajo con fuego y las cosas de la guerra y el latrocinio [...] de las gemas la cornalina y todas las piedras rojo oscuro; de los minerales el arsénico, el fósforo, el petróleo, el cristal y el cobre rojo" ("Saturnus [... et ex lapidibus alianza et omnes lapides nigros; et ex metallis plumbum, ferrum et omnia nigra et fetida [...] Iupiter [...] ex metallis stannum et tuciam; et ex arboribus nuces et avellanas, pinos, [...] Mars [...] ex magisteriis laborantes fe- 
mia no se limitaba a la transformación de la naturaleza sensible, sino también de la espiritual. ${ }^{97}$

Es preciso recordar que durante el siglo XIII los alquimistas fueron aquellos hombres dedicados al trabajo de los metales, especializados en el tratamiento de las sustancias químicas, ${ }^{98}$ en la destilación y sobre todo, en la transformación de las cosas. ${ }^{99}$ En el siglo XIII, Vincent de Beauvais (II9Oca.1264) describe la alquimia como rationum vel causarum investigatio, es decir, estudios del fundamento teórico de la filosofía natural, cuyo desarrollo en gran parte se dio gracias a los escritos de Aristóteles transmitidos por medio de Avicena (980-IO37), filósofo y médico quien retoma los conocimientos de la alquimia en sus tratados de práctica médica. ${ }^{100}$

rrum cum igne et arma bellica et latrocinia [...] ex lapidibus alaquech et omnes lapides rubeos et obscuros; et ex metallis azernech [...] et sulfur et naft el vitrum et es rubeum"), en Picatrix: the Latin Version, 150-153.

97. Burckhardt piensa que la adopción cristiana de la alquimia debe buscarse en las ideas cosmológicas propias de la alquimia, pues éstas se refieren tanto a la naturaleza externa (metálica o simplemente mineral), como a la naturaleza interna o del alma, es decir, se ligan de manera orgánica a la antigua metalurgia, motivo por el cual dicho fondo espiritual fue aceptado como un conocimiento de la naturaleza (physis) en el más amplio sentido de la palabra, junto con las técnicas del oficio; de la misma manera en que el cristianismo y el islamismo incorporaron el legado pitagórico que encerraban la música y la arquitectura a su mundo espiritual. Burckhardt, Alquimia, 6. Para el tránsito de la alquimia de la antigüedad clásica al mundo romano cristiano, al musulmán y hasta el Renacimiento véase Picatrix: the Latin Version.

98. Por Vincent de Beauvais se sabe que para mediados del siglo XIII, los alquimistas eran artífices especializados en profesiones como el trabajo mineral y la medicina, lo cual detalla en su Speculum naturale. Al principio de su capítulo De operatione vermilionis et cinabri et auricalci menciona que estos trabajadores de la alquimia deben ser descritos porque tratan el cambio de las cosas propter rerum transmutatione. Obrist, "Die Alchemy", 42.

99. Durante la temprana Edad Media circuló un manual que incluía recetas alquímicas de fuentes griegas conocido como el Mappae clavicula. Burnett, "The Astrologer's Assay", io5. El primer texto alquímico latino es el Liber Morieni de Robert de Chester II44, en Burnett, "The Astrologer's Assay", I04. Luego apareció el texto Pretiosa margarita novella, el cual compilaba manuscritos alquímicos datables desde I330. Éste fue impreso en 1546 en Venecia. Willard, “The Metamorphosis of Metals", I52. Hugo de Santalla es el traductor de la Tabula smaragdina de Hermes Trismegisto. El misterioso texto había sido considerado como clave para el esoterismo alquímico y es la culminación de la revelación hermética en los Secretos de la naturaleza de Pseudo-Apolonio, el cual Santalla tradujo del árabe, Willard, "The Metamorphosis of Metals", I05. Obrist considera que el hecho de que el hombre se esfuerce por alcanzar un conocimiento teórico base para la conversión de los cuerpos significa que este hecho había alcanzado el estatus de verdad. Obrist, "Die Alchemy", 45.

ıоo. Alfredo, el Inglés, traduce del árabe al latín el texto de Avicena sobre ciencia natural, 


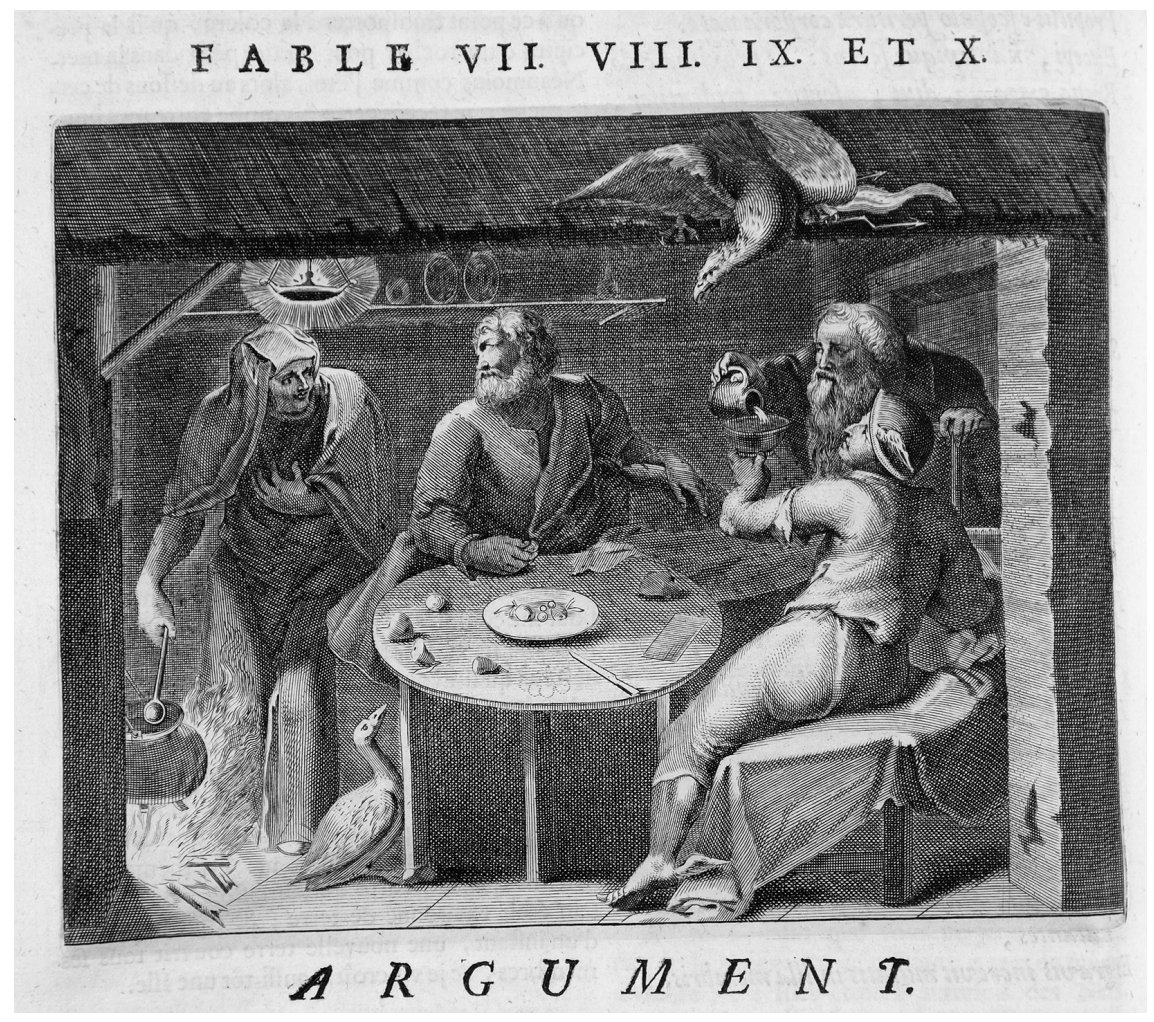

6. Otto van Veen, Filemón y Baucis, tomada de Quinti Horatii Flacci Emblemata (Amberes: Ex Officina Hieronymi Verdussen, 1607), placa 87. Colección Fotográfica del Warburg Institute.

en I200, "Apenas ahora, en el curso de la recepción general de la ciencia natural aristotélica, las teorías alquímicas alcanzan un efecto más amplio en el marco de las instituciones universitarias" ("Erst jetzt, im Zuge der Gesamtrezeption der aristotelischen Naturwissenschaft, erlangen die alchemistischen Theorien im Rahmen der universitären Institution eine breitere Wirkung”), en Obrist, "Die Alchemy", 40. Sobre los tratados de Avicena, véase Dimitri Gutas, Avicenna and the Aristotelian Tradition: Introduction to Reading Avicenna's Philosophical Works (Leiden: Brill, 20I4); Avicenna, The Metaphysics of the Healing: a Parallel English-Arabic Text = al-Shifä: al-Ilahiyāt, trad. Michael E. Marmura (Utah: Brigham Young University Press, 2005); Avicenna, Liber primus naturalium. Tractatus secundus de motu et de consimilibus, eds. A. Allard, J. Janssens y S. van Riet (Bruselas: Académie Royale de Belgique, 2006). 
A decir de Burckhardt, la alquimia, aprehendida desde una aproximación cristiana, identificaría la piedra filosofal, capaz de convertir los metales ordinarios en oro o plata, con la representación de Cristo, pues "su obtención por medio del 'fuego que no quema' del azufre y del 'agua consistente' del mercurio, simboliza el nacimiento del Cristo". ${ }^{\text {Ior }}$

Los cuatro elementos ilustrados sobre la mesa del Mago —el vaso, el cuchillo, los dos cubos y la masa blanca con forma de plumas - podrían ser los cuatro elementos - agua, fuego, tierra y aire correspondientemente- como componentes del espíritu de la naturaleza perfecta. En el Picatrix se menciona el proceso de invocación de la naturaleza perfecta, como espíritu. Se le debe llamar por su nombre, que es el de los cuatro elementos de la naturaleza: Meegus, Betzahuech, Vacdez y Nufeneguediz. El texto luego menciona una receta donde se deben mezclar varios elementos con vino, el cual se debe verter en cuatro cántaros y colocarlos en las cuatro direcciones de la mesa de trabajo. ${ }^{102} \mathrm{La}$ labor del Mago, como aquella de crear imágenes que engañen y perturben la realidad, se asemeja a la labor del alquimista, quien transforma la materia en la búsqueda de alterar su realidad.

\section{Los hijos de los planetas}

Las acepciones astrológicas en la representación del triunfo El Mago se hicieron a partir de representaciones de los hijos de los planetas, basadas en el conocimiento astrológico.$^{\mathrm{IO} 3}$ Fritz Saxl dice que la tradición de representar a los hijos de los planetas proviene de la Roma clásica, ${ }^{\mathrm{IO}}{ }^{\mathrm{O}}$ de donde se extendió al Medio

IOI. Burckhardt, Alquimia, 7 .

I02. Picatrix: the Latin Version, I.

I03. "Las pinturas de los hijos de los planetas" se constituyeron en un género de pinturas decorativas, de acuerdo con la simbología de la tradición astrológica de ilustrar en copiosas alegorías las influencias de los movimientos planetarios sobre la vida de los hombres. Lippman, Die sieben Planeten, I.

I04. Para estudiar la producción del Medio Oriente utiliza el manuscrito de la cosmografía de Kaswînî, a partir de las copias más antiguas que han perdurado. La copia ilustrada más antigua que nos ha llegado de esta obra es el Monac. Arab. 464 (ff. Ior-I7r), escrito en Damasco en 1366. Los manuscritos iluminados de la cosmografía de Kaswînî y su traducción al persa muestran que había una conformidad con los tipos de representaciones de los planetas y de sus hijos. Por ello y porque en este manuscrito no hay trabajos con compás y líneas, sino claramente se encuentran escenas de vida, son las razones por las que Saxl consideró que el manuscrito de la cosmografía 
Oriente — Bagdad, Turquía - y que luego emprendió un viaje de regreso a Europa ${ }^{\text {Ios }}$ Los ejemplos que da para esta afirmación son los frescos de Padua, que contienen escenas del zodiaco ya para el siglo XIv. ${ }^{\text {I06 }}$

Para Saxl el estilo de representar a los hijos de los planetas en forma de compendio llegó de Oriente. Cada planeta tenía bajo su autoridad siete oficios, los

de Kazwînî no fue la primera en concebir el diseño, sino que ya para este tiempo las representaciones de los hijos de los planetas eran un modelo convencional. Véase Fritz Saxl, "Probleme der Planetenkinderbilder", Kunstchronik und Kunstmarkt, núm. 48 (26 de septiembre de 1919): I026. I05. A partir del siglo XII, España y Sicilia fueron dos importantes centros de esta difusión. I06. El Palazzo della Ragione en el centro de Padua fue el punto de encuentro de la vida privada y civil del siglo XII y XIII. Dentro de sus paredes se administraba la justicia y se llevaba a cabo el comercio. Construido alrededor de I2I8 y decorado alrededor de 1306 con un ciclo de frescos de Giotto que se extiende a lo largo de 600 metros. Vale la pena citar la descripción que hace Graziella Vescovini: "Una lápida recuerda cómo la concepción del ciclo con frescos se rehace según la teoría de Pedro de Abano [...]. Los frescos son articulados en un esquema de dos órdenes conceptualmente interdependientes uno del otro. El primer orden, el superior, describe las imágenes del cielo astronómico; el segundo orden, en cambio, el inferior, describe las características de la influencia que de tales imágenes derivan en la vida del hombre. En el primer orden del ciclo zodiacal son representados tres elementos. El primero es la representación de la figura del Firmamento o de las Constelaciones mayores, 36 en total [...] marcadas por el movimiento aparente del sol durante el año (año Sideral). El segundo elemento es la descripción de las representaciones del mes según las figuras de los Signos, en total doce. El tercer elemento es la descripción de las figuras que representan el Día, determinado por la posición del astro más brillante de la constelación propia de cada signo, fijo sobre la Hora del Mediodía según la particular teoría astrológica del Ascendente: el Ascendente, según una concepción medieval, es dado por nacimientos diurnos o nocturnos, en la posición o grado del cielo al Mediodía o a la Medianoche de cada día del mes y luego del ańo." ("Une lapide ricorda come la concezione del ciclo affrescato si rifacesse alle teorie di Pietro d'Abano [...]. Gli affreschi sono articolati in uno schema di due ordini concettualmente interdipendenti tra di loro. Il primo ordine, quello superiore, descrive le immagini del cielo astronomico; il secondo ordine, invece, quello inferiore descrive le caratteristiche delle influenze che da tali immagini derivano nella vita dell'uomo. Nel primo ordine del ciclo zodiacale sono rappresentati tre elementi. Il primo è la rappresentazione delle figure del Firmamento o delle Costellazioni maggiori, 36 in tutto [...] scandite dal moto apparente del sole durante l'anno (anno Sidereo). Il secondo elemento è la descrizione delle raffigurazioni del mese secondo le figure dei Segni, in tutto dodici. Il terzo elemento è la descrizione delle figure che rappresentano il Giorno, determinato dalla posizione dell'astro più lucente della costellazione propria di ogni segno fissato sull'ora (Ora) di Mezzogiorno secondo la particolare teoria astrologica dell'Ascendente: l'Ascendente, secondo una concezione medievale è dato, per nascite diurne o notturne, dalla posizione o grado del cielo al Mezzogiorno o alla Mezzanotte di ogni giorno del mese e quindi dell'anno"), en Graziella Vescovini, L’uomo, la terra e gli astri, Gli afreschi del Palazzo della Ragione a Padova (Brugine: Centro Internazionale di Storia dello Spazio e del Tempo, Istituto Poligrafico e Zecca dello Stato, 1989). 
cuales fueron personificados. Estas representaciones luego se europeizaron y se transmitieron por medio de manuscritos. ${ }^{107}$ Friedrich Lippman, por su parte, considera que la producción europea de las representaciones de los hijos de los planetas se originó en Italia a mediados del siglo xv, tal vez en Florencia, desde donde se extendió a los Países Bajos y a Alemania, y preservó sus características a lo largo de la primera mitad del siglo Xvi. ${ }^{\mathrm{I} 8}$

Las representaciones de los dioses grecorromanos, o como lo llama Aby Warburg, "la supervivencia de los dioses antiguos" se dio en dos sentidos, como alegorías morales — como las interpretaciones alegóricas de Ovidio-y por medio de la astrología. ${ }^{109}$ Durante la Edad Media este tipo se representaciones se encuentran en fachadas de iglesias y catedrales, especialmente relaciona-

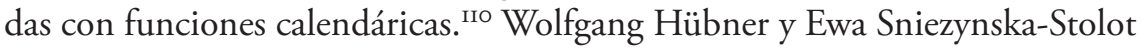
encontraron imágenes astrológicas en manuscritos, como salterios, simbolizadas en las drôleries, ${ }^{\mathrm{III}}$ incluidas ya fuera con el objetivo de ilustrar el desarrollo espiritual del hombre, o el de servir a fines mágicos — como la adivinación del futuro- o incluso a la práctica de exorcismos mediante la influencia astral. De cualquier manera, el desarrollo de las drôleries fue posible gracias a la unión

I07. Saxl, "Probleme der Planetenkinderbilder", Ior6.

I08. Lippman, Die sieben Planeten, I.

I09. "Las representaciones de los dioses en el primer Renacimiento florentino dependen en su totalidad, en mayor o menor medida, de las listas de divinidades de la Antigüedad tardía”, en Aby Warburg, "El mundo de los dioses antiguos y el primer Renacimiento en el norte y en el sur (1908)", en Warburg, El renacimiento del paganismo, 409. A decir de Warburg, las representaciones astrológicas como personificaciones de las deidades grecorromanas tomaron su base a partir de las esculturas antiguas: "Así lo demuestran, por ejemplo, las figuras astrales de la capilla del Santísimo Sacramento de Rímini a las que anima el pathos de los sarcófagos de la Antigüedad tardía; y este mismo pathos es la fuente de una estampa norditaliana de la Muerte de Orfeo cuyo único ejemplar conocido se conserva en el Kunsthalle de Hamburgo", Warburg, El renacimiento del paganismo.

IIo. Sobre el tema, véase Perrine Mane, Calendriers et Techniques agricoles (France-Italie, XII ${ }^{\mathrm{e}}$-XIII ${ }^{\mathrm{e}}$ siècles) (París: Le Sycomore, I983). Shapiro pone énfasis en la tradición oral y el papel de la instrucción del artista que realiza la obra. Meyer Shapiro, Words and Pictures, On the Literal and the Symbolic in the Illustration of a Text (La Haya y París: Mounton, 1973).

III. Su probable origen es Inglaterra durante el siglo II. Boll, Saxl, Panofsky y Seznec consideran que las drôleries sirven para expresar el concepto de universo, sin embargo, Sniezynska-Stolot considera que estas imágenes son las constelaciones o las partes de ellas que acompañan los tres decanatos de cada signo, conclusión a la que llegó al tomar como base los tratados astrológicos griegos (Arato, Ptolomeo, Teucro y Atioco), los árabes (Albumasar) y el medieval (Miguel Escoto). Sniezynska-Stolot, "Christian Interpretation of the Zodiac", 97. Véase también Wolfgang Hübner, “Das Horoskop der Christen 'Zenor, 38 L.'”, Vigiliae Christianae 29, núm. 2 (junio, 1975): I20-I37. 
de dos autoridades antiguas, la astrología y el Antiguo Testamento. ${ }^{\mathrm{II}}$ En este contexto, los salterios de Bohemia fueron pioneros en la práctica de plasmar ideas cristianas utilizando signos zodiacales.

Es probable que el tarot pudiera haber ejemplificado un fin similar, si hubiese sido objeto de prácticas como el nicodemismo, aunque especialmente éste fue percibido en los círculos de los spirituali entre 1540 y 1550 en Francia, Alemania e Italia. ${ }^{\mathrm{II} 3}$ Para esta doctrina, las ceremonias y los sacramentos se volvían símbolos, imágenes carnales que debían ser interpretadas de manera espiritual, de tal forma que dejaban de ser sólo imágenes representacionales o alegorías. ${ }^{\text {II4 }}$

Conviene en este punto recordar las manchas que llegan a presentar los triunfos dorados de los mazos visconteos, los cuales, si se acepta la hipótesis que los identifica como talismanes, podrían deberse a esfugimaciones realizadas con diversos materiales orgánicos, sin embargo, es posible también que sean resultado de reacciones ácidas accidentales producto de las condiciones históricas en que se conservaron las cartas. Para determinar este punto es necesario hacer un análisis químico de los pigmentos que determinen el grado de aleación del oro que se usó en la elaboración de la carta, así como de los químicos que conforman sus pigmentos y sus reacciones.

Las cartas no tenían nombre, sin embargo, como es posible suponer, sus usuarios conocían la imagen que estaba expresando. Ya Warburg expresaba que el tarot de Mantegna (norte de Italia, segunda mitad del siglo Xv) mostraba un periodo de transición formal en la representación de los dioses grecorromanos, entre el literalismo medieval y el idealismo renacentista. ${ }^{\mathrm{II}} \mathrm{Si}$, por una parte, las cartas fueron únicamente usadas para jugar, sólo hubiera sido necesaria una nomenclatura consensuada. Si por el contrario, las cartas hechas como objetos

II2. Sniezynska-Stolot, "Christian Interpretation of the Zodiac", IoI.

II3. El nicodemismo es una doctrina de disimulo religioso que por una parte incita a la gente reformada a esconder sus propias convicciones bajo prácticas simulativas para escapar de la persecución, el martirio y el exilio; por otra parte, trata de dar soporte teológico a su actitud pragmática. Se basa en pasajes bíblicos, así como en la posición de Orígenes, usada por Erasmo respecto a la diferencia entre el exterior carnal del hombre, el adiaphoron estoico y el interior espiritual del hombre. Véase "Achille Bocchi's Symbolicae Quaestiones", I24.

II4. Véase Carlo Ginzburg, Il nicodemismo: simulazione e dissimulazione religiosa nell'Europa del 'Soo (Turín: G. Einaudi, 1970); y Paolo Simoncelli, Evangelismo italiano del Cinquecento: questione religiosa e nicodemismo politico (Roma: Istituto Storico Italiano per L'età Moderna e Contemporanea, 1979).

II5. "Venus, por ejemplo, se representa a la manera medieval, mientras que Mercurio ha adoptado ya las formas antiguas", en Warburg, "El mundo de los dioses antiguos", 409. 
suntuosos eran utilizadas de acuerdo con su contenido filosófico o con algún tipo de magia que implicara súplicas e invocaciones, ${ }^{\mathrm{II}}$ la falta del nombre sólo puede explicarse como un medio para guiar al usuario mediante una enseñanza oral y una interpretación con significado personal.

Richard Kieckhefer analiza los libros de magia de la Edad Media y nota que aunque permanecieron anónimos aparentemente con el fin de mantener su sacralidad y poder, en tanto objeto mágico, debieron haber sido también consagrados y guardados celosamente por sus poseedores. ${ }^{I 17}$ La práctica de la magia, a decir de Kieckhefer, puede entenderse desde su función y significado cultural, así como desde las reacciones que suscitó tanto entre sus detractores como entre los acusados. Así, el papel de la magia se explica en referencia a la cosmovisión de la sociedad que la contiene.

Cabe rescatar en este punto que el elemento que aporta información más clara sobre las cartas es la inclusión de los escudos de armas de Visconti y de Saboya. Se tiene noticia de que en 1320 a Matteo y Galeazzo Visconti se les acusó de uso de necromancia en contra del papa Juan cuando un testigo dijo que se le había enseñado un libro lleno de recetas de amor, odio y algunas para encontrar objetos perdidos. ${ }^{\text {II8 }}$ De igual modo, en la biografía que hace Decembrio de Filippo Maria Visconti cuenta que por sus temores nocturnos a fantasmas necesitaba que un guardia cuidara su sueño. ${ }^{\text {II9 }}$ Decembrio también relata que Visconti era muy supersticioso, ${ }^{120}$ Filippo Maria portaba una medalla de

II6. Como el Ars notoria, la cual emplea rezos e invocaciones a los ángeles para ganar maestría en las artes liberales y mecánicas. Thorndike citado en Kieckhefer, Forbidden Rites, I2O.

II7. Kieckhefer, Forbidden Rites, 5 .

II8. Kieckhefer, Forbidden Rites, I.

II9. "A menudo, cansado por el insomnio, se reducía a ir y venir de la habitación anhelando dormir, con los suyos, que mientras tanto le debían hacer compañía [...] Otra razón de temor: oír cantar a las aves de modo insólito, especialmente de noche" ("Spesso, spossato dall'insonnia, si riduceva ad andare avanti e indietro per la camera bramando di dormire, con i suoi che intanto gli dovevano fare compagnia [...] Altra ragione di timore: sentir cantare gli uccelli in modi insoliti, specialmente di notte"), en Decembrio, Vita di Filippo Maria Visconti, I2O.

I20. "Hizo cortar los serbales en todas partes donde fuera que se encontraran, afirmando haber descubierto que su sombra era un incentivo de peste, por el color, que había debido portar los coléricos influjos. Y ahora: ordenó exterminar a todos los cuervos, fijando una recompensa por cada ejemplar puesto bajo sus ojos. Ninguno podía poner pie en aquella zona de la habitación, aislada del resto mediante un signo, ahí donde Silvestro, cubiculario por un tiempo, yació enfermo antes de morir [...] 'Y no permitió que ninguno, enfermo o contagiado, se parara en la corte" " ("Fece tagliare i sorbi dovunque si trovassero, asserendo d'aver appreso che la loro ombra era un incentivo di peste per color che ne aveva dovuti sopportare i rabbiosi influssi. E ancora: 
oro de santa Bárbara, patrona de la artillería, en donde hizo figurar motivos estelares. ${ }^{121}$ Asimismo, el duque tuvo gran consideración hacia los astrólogos, a quienes consultaba antes de realizar cualquier empresa, pues creía que todo sucedía por un destino. ${ }^{122}$

Decembrio narra también que Filippo Maria solía aislarse en las cámaras internas de su palacio durante el novilunio y el plenilunio, ${ }^{\mathrm{I} 23}$ momentos de especial importancia en las prácticas mágicas. ${ }^{124}$

El tarot perteneciente a Filippo Maria debió haber recibido un uso particular, por la iconografía anteriormente descrita. Los triunfos del mazo Visconti di Modrone, así como las cartas en general del mazo Visconti-Sforza tienen un pequeño agujero en el centro del margen superior. Por las características que presenta la pintura, es posible determinar que el orificio fue hecho posteriormente a la realización de las cartas. Es viable proponer que se hizo para colgar las cartas ordenándolas en determinada secuencia, que bien pudo haber sido cambiante. El tarot de Mantegna, conocido por su contenido neoplatónico, también tiene esta serie de agujeros en el centro del margen superior.

Si el orden de las cartas de los tarots visconteos fuera lineal y siguiera el propuesto por la Ludi inductio, El Loco sería un personaje que se movería en la escala de las triunfos, iniciando con El Mago, y pasaría por las virtudes, las etapas de los hombres, La Muerte y La Resurrección hasta El Ángel; podría considerarse que los mazos del tarot visconteo son un juego ético con enseñanzas religiosas, como el tarot de Mantegna. ${ }^{\mathrm{I} 25}$

ordinò di sterminare tutti i corvi, fissando una ricompensa per ogni esemplare messogli sotto gli occhi. Nessuno poteva porre piede in quella zona della camera, isolata dal resto mediante un segno, lì dove Silvestro, un tempo cubiculario, era giaciuto ammalato prima di morire. [...] 'E non permise che nessuno, ammalato o contagiato, si spegnesse a corte'"), en Decembrio, Vita di Filippo Maria Visconti, $2 \mathrm{I2}$.

I2I. Filippo Maria también hizo construir en su honor una capellanía en el monasterio de San Sixto el I mayo de I434. Decembrio, Vita di Filippo Maria Visconti, 4I9.

I22. Sus astrólogos eran Pietro Lapini da Montalcino, médico del papa Juan XXIII, astrólogo, profesor en Pavia, y algunas veces encargado de misiones diplomáticas; Stefano Fantucci de Faenza, médico y astrólogo del duca, quien alrededor de 1427 fue profesor en Pavia; Antonio de Bernadigio (o Bernaregio), también profesor de medicina y astrología. Entre sus médicos se encontraba también Elías, el Hebreo, médico del papa Martín V y de Eugenio IV, quien debió pasar al servicio de Visconti alrededor de I438. Decembrio, Vita di Filippo Maria Visconti, 2I2-2I3.

I23. Decembrio, Vita di Filippo Maria Visconti, I24.

I24. Picatrix. Un Traité de magie médiéval, 215.

I25. En el Salmo 52 se menciona que: "El loco dice en su corazón: no existe Dios". La figura del Loco posee también un aspecto místico-sacro. La Espístola a los Corintios gozaba en el Re- 
$\mathrm{Si}$, por otra parte, el orden que siguiera no fuera lineal, podría estar sujeto a una disposición con base en el triunfo de La rueda de la fortuna (fig. 7), ${ }^{126}$ que por una parte explica el papel del destino en la vida del hombre, así como también se usa para ejemplificar los movimientos de ascenso y descenso de los planetas mediante el zodiaco. ${ }^{127}$

nacimiento de una gran importancia. Algunos de sus pasajes reflejan la relación existente entre la locura y el Divino: "La palabra de la cruz para aquellos que se perdonan es una locura" (I, I,I8); "Ninguno se engaña a sí mismo: si alguno entre ustedes cree ser sabio en la sabiduría de este siglo, se vuelve loco por ser conocedor. Porque la sabiduría de este mundo frente a Dios es locura” (I, 3, I8-19). Sólo la renuncia de sí y los propios bienes materiales puede, según el pensamiento cristiano, conducir del hombre a Dios. El Loco, por esta prerrogativa, se consideraba un inspirado que se encontraba a un paso del Divino. La presencia del Loco en la lista de los triunfos adquiere un significado preciso: del loco no creyente al "Loco de Dios" o "Loco divino", como se volvió el santo popular san Francisco, quien fue llamado "el Santo Juglar de Dios", véase Vitali, "Ludus triumphorum e tarocchi”, I3.

I26. Sobre La rueda de la Fortuna véase Vitali, "Ludus triomphorum e tarocchi", I2.

127. En el Tetrabiblos de Ptolomeo se puede ver este aspecto "Tales, entonces, son las afinidades naturales de las estrellas y los signos del zodiaco. Se dice que los planetas están en su 'propia fase' cuando un planeta individual mantiene al sol o a la luna el mismo aspecto que su casa tiene a sus casas; por ejemplo, cuando Venus está en sextil a las luminarias, siempre que esté occidental al sol y oriental a la luna, de acuerdo con el arreglo original de sus casas. Se dice que están en sus propios 'carros' y 'tronos' y entonces como cuando sucede que ellos tienen familiaridad en dos o más de las formas mencionadas con los lugares en los cuales se encuentran; pues entonces su poder de efectividad es acrecentado por la similitud y cooperación de las propiedades afines de los signos que las contienen. Dicen que ellos 'se alegran' cuando, incluso aunque los signos que contienen no poseen familiaridad con las estrellas en la misma sección; en este caso la simpatía surge menos directamente. Ellos participan, sin embargo, en la similitud de la misma manera; justo como, por el contrario, cuando se encuentran en regiones ajenas pertenecientes a la sección opuesta, una gran parte de su propio poder es paralizado, porque el temperamento que surge de la disimilitud de los signos produce una naturaleza diferente y adulterada" ("Such, then, are the natural affinities of the stars and the signs of the zodiac. The planets are said to be in their 'proper face' when an individual planet keeps to the sun or moon the same aspect which its house has to their houses; as, for example, when Venus is in sextile to the luminaries, provided that she is occidental to the sun and oriental to the moon, in accordance with the original arrangement of their houses. They are said to be in their own 'chariots' and 'thrones' and then like when they happened to have familiarity in two or more of the aforesaid ways with the places in which they are found; for then their power is most increased in effectiveness by the similarity and co-operation of the kindred property of the signs which contain them. They say they 'rejoice' when, even though the containing signs have no familiarity with the stars of the same sect; in this case the sympathy arises less directly. They share, however, in the similarity in the same way; just as, on the contrary, when they are found in alien regions belonging to the opposite sect, a great part of their proper power is paralysed, because the temperament which arises from the dissimilarity of 
DOI: http://dx.doi.org/10.22201/iie.18703062e.2018.112.2635

MODELOS DE LA IMAGEN

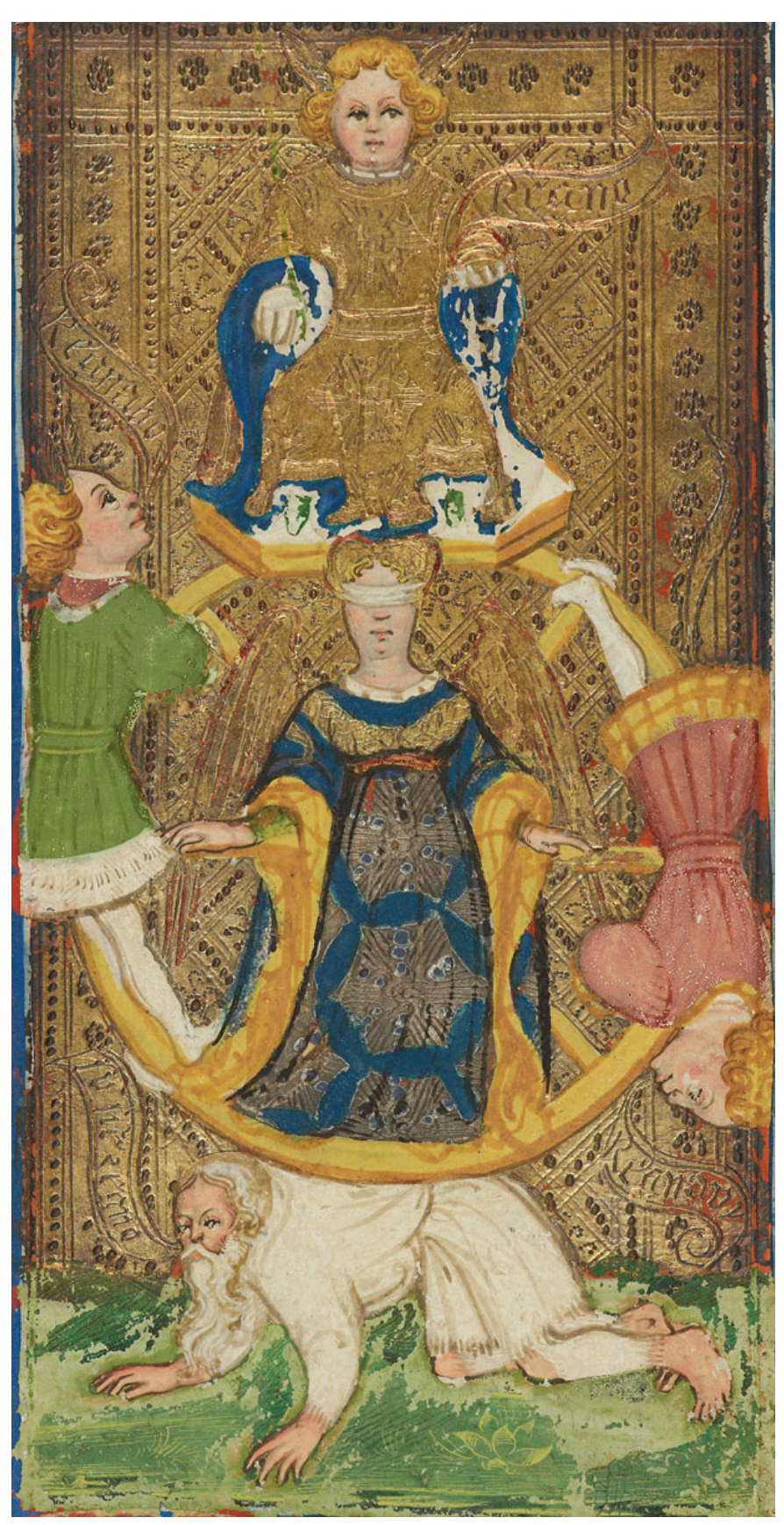

7. Bonifacio Bembo, La rueda de la fortuna, Italia, ca. I442I445, miniatura con taroccato, cartas del Tarot Visconti. The Morgan Library \& Museum,

Nueva York, MS M.630.9). 
DOI: http://dx.doi.org/10.22201/iie.18703062e.2018.112.2635

176

VANESSA ALVAREZ PORTUGAL

Consideraciones finales

El tarot Visconti, con sus tres mazos, es hasta ahora el tarot más antiguo que se conoce, y es el que sentó los modelos iconográficos de los mazos posteriores. Aunque como se ha mencionado anteriormente, hay muchas incógnitas respecto al origen de los mazos, y hasta que no se realicen análisis pictóricos a las miniaturas, los estudios comparativos de estilo e iconográficos constituyen las herramientas para ubicar al tarot en el Renacimiento italiano temprano y proponer una posible autoría. El tarot habla por medio de sus imágenes, presenta motos y heráldica viscontea, lo que permite identificar a su dueño y ubicarlo en un espacio temporal definido. El conocimiento del contexto en el que surgió es, hasta el momento, la mejor fuente para el estudio de los tarots Visconti. El reconocimiento de la influencia que la astrología, el neoplatonismo, la magia y la doctrina religiosa tuvieron en el cristianismo del Renacimiento temprano permite identificar tres aspectos del tarot Visconti: el primero es su papel como juego que representa condiciones humanas; el segundo, su contenido iconográfico astrológico, derivado de teorías e imágenes provenientes de tradiciones intelectuales occidentales y orientales; y el tercero, su posible estatus de objeto de edificación espiritual.

El Istruzioni necessarie per chi volesse imparare il ginoco dilettevole delli tarocchini di Bologna, de Carlo Pisarri, presenta los triunfos ordenados según la tradición filosófica ecléctica del Renacimiento de alto contenido neoplatónico, de tal forma que es lógico pensar que una persona instruida en dicha corriente filosófica podía entender y desplazarse ágilmente entre las múltiples reglas que podía adoptar el tarot como juego.

El contenido de imágenes astrológicas en las cartas del tarot no se acaba en el ejemplo presentado en este trabajo, se puede mencionar la presencia de Saturno en el Ermitańo; Acuario o la Luna en la carta de La Templanza; de Marte o Júpiter en El Emperador; o de La Rueda de la Fortuna como representación de los planetas en el zodiaco, como se refirió anteriormente. ${ }^{228}$

the signs produces a different and adulterated nature"), en Ptolomeo, Tetrabiblos, ed. F.E. Robbins (Cambridge, Mass., y Londres: Harvard University Press/William Heinemann Ltd., 1980), I3.

I28. Es abundante la bibliografía que trata esta relación en cartas de tarots posteriores, sólo por mencionar algunos véase Jean Huets y Stuart R. Kaplan, The Encyclopedia of Tarot, 4 vols. (Game Systems, 1978); Germano Mulazzani, I tarocchi viscontei e Bonifacio Bembo (Milán: Amilcare Pizzi-Cinisello B., I98I); Michael Dummett, Il mondo e l'angelo i tarocchi e la loro storia (Nápoles: Bibliopolis, 1993); y Michael Dummett, The Game of Tarot: from Ferrara to Salt Lake 
Resulta sorprendente que no se tenga noticia en el siglo XV de algún documento que refiera la existencia de los mazos visconteos, en tanto que hay documentos probatorios de la presencia de naipes desde el siglo XIV. A pesar de todo, no considero que los mazos de Visconti fuesen totalmente secretos, pues de alguna forma, aunque los modelos de los triunfos provienen de tradiciones anteriores, éstos se esparcieron y se instalaron en: el Minchiate (Florencia, I447); el tarot de Mantegna (Mantua, I460); y el tarot de Carlos VI (Francia, entre I470-I480) por mencionar algunos. El contrato de secrecía para la elaboración de triunfos y cartas de juego, realizado en 1477 entre Roberto Blanchelli y el pintor Pietro Bonozzi, brinda mucha luz al respecto. La técnica de los cartolieri debe cuidarse por motivos económicos. Los mazos visconteos no se imprimieron sino que se realizaron con la técnica de la miniatura. Por otra parte, tanto la dureza del cartón con que fueron hechas las cartas, como el estado de conservación en el que se encuentran, indican que no fueron arduamente manipulados. Por la técnica empleada, temple que soporta metales como el oro y la plata, además del decorado con punzón, es posible pensar que estas cartas se hicieron para apreciarse, para observarse.

En el estudio de la carta del triunfo del Mago se puede observar una concentración de elementos astrológicos, neoplatónicos, herméticos y de cábala cristiana propios del ambiente cultural del Renacimiento temprano del norte de Italia, representados a su vez en un estilo e iconografía medieval. En la relación de la imagen con las representaciones de los hijos de los planetas, podemos percatarnos del recorrido de los elementos iconográficos astrológicos, de la antigua Roma, al Medio Oriente y de vuelta a Europa, como parte de la movilidad del conocimiento y de la cultura en el mundo antiguo.

El estudio del contexto cultural de la corte milanesa, así como de las fuentes documentales, ha permitido proponer posibles usos que recibió el triunfo, así, la imagen del prestidigitador pudo haber servido para la práctica tanto de la memoria como de la magia.

Hay un elemento que vale la pena retomar, éste es el agujero de la parte central superior de los triunfos, presente en la carta de El Mago. Como se subrayó anteriormente, éste fue hecho con posterioridad a la realización de las cartas, probablemente para colgarlas, lo cual marca un empleo específico por parte de los propietarios de los mazos. Considero pertinente equiparar los mazos viscon-

City (Londres: Duckworth, 1980); Andrea Ascari y Andrea Vitali, eds., Tarocchi le carte del regno, la storia, i simboli, il mito (Faenza: Edizioni Le Tarot, 1997). 
teos con los libros de magia. Estos últimos eran anónimos; culturalmente se les adscribía poder operativo que devenía de su consagración por parte de sus poseedores, aunque el poder lo podían perder si los libros llegaban a ser conocidos por muchas personas. De manera paralela, los mazos visconteos también son en parte anónimos, fueron ampliamente desconocidos y contienen en su iconografía la heráldica de su poseedor que establecía así un vínculo entre el objeto y el sujeto.

Las invocaciones a diversos daemones sobre las que asesora el Picatrix, como práctica de la magia talismánica, o las del Ars notoria que menciona Kieckhefer, ${ }^{129}$ tienen en común la presencia de personajes de sacralidad dudosa a quienes se dirigen las súplicas. Los daemones son la fuente a la que se recurre en la magia talismánica y, por medio de las representaciones astrológicas de sus triunfos, en el tarot. Conviene retomar que el neoplatonismo explica la relación del hombre con el cosmos, de tal forma que cada elemento de la creación tiene su lugar en la escala divina — cuyo centro y fin es Dios (la Unidad) — y los astros, en tanto que seres celestes, tienen un rango más elevado que el hombre y la naturaleza. Esta escala permite comprender el sistema de influencias entre los seres creados como consecuencia de las emanaciones divinas. En el Renacimiento este conocimiento, considerado sagrado y revelado, se fusionó con el cristianismo y las tradiciones mágicas de la antigüedad grecorromana que habían sobrevivido. Es cierto que, así, el neoplatonismo renacentista floreció entre una élite intelectual, la cual, no obstante, fue también heredera junto con el resto de la población de prácticas supersticiosas antiguas. Éste es un rasgo que debe mantenerse en cuenta.

El tarot se desenvuelve en una dualidad. Dualidad de uso, azaroso o educativo, de ars memoria o notoria, entre el pueblo y la élite, entre el intelectual y el supersticioso. Sus triunfos comparten la misma suerte. En la medida en que presentan un repertorio de imágenes más antiguas, probablemente permi-

I29. Como ejercicio que pide ayuda a la Virgen y a los ángeles caídos, "Aunque el ars notoria no invocaba ayuda demonológica, y ostensiblemente giró en torno a la recitación de devociones a la Virgen y a los ángeles no caídos, sus técnicas fueron poco tradicionales y supersticiosas, y un observador antipático, perdonablemente, pudo haberla categorizado con este primer experimento en el manual de Múnich" ("Although the ars notoria did not call upon demonic aid, and ostensibly revolved around the recitation of devotions to the Virgin and to unfallen angels, its techniques were untraditional and superstitious, and an unsympathetic observer might pardonably have categorized it with this first experiment in the Munich handbook"), en Kieckhefer, Forbidden Rites, I2O. 
tieron el reconocimiento de ideas pasadas. Se puede considerar que no existió un manual explicativo de los motivos de los triunfos del tarot - puesto que la primera mención que se hace de los elementos filosóficos es la de Pierre Grégoire en el siglo xvI-, de tal forma que la explicación de la imagen se propagó por medio de la palabra, y permitió con ello diversos matices de interpretación individual y probablemente empírica, que dependería del grado de erudición de la persona.

Con el tiempo, las imágenes de los triunfos cobraron una dinámica propia. Por medio de la creación de diversos mazos de tarots a lo largo de los años, sufrieron variaciones iconográficas, e hicieron posible el desarrollo de un amplio campo de interpretaciones y comentarios cuyo necesario estudio indudablemente enriquece el conocimiento de la cultura humana. \$ 